University of Nebraska - Lincoln

DigitalCommons@University of Nebraska - Lincoln

\title{
Seasonal energy and water balance of a Phragmites australis-dominated wetland in the Republican River basin of south-central Nebraska (USA)
}

\author{
John D. Lenters \\ University of Nebraska-Lincoln, john.lenters@colorado.edu \\ Gregory J. Cutrell \\ University of Nebraska - Lincoln, greg.cutrell@gmail.com \\ Erkan Istanbulluoglu \\ University of Washington, Seattle, erkani@u.washington.edu \\ Durelle T. Scott \\ Virginia Tech University, dscott@vt.edu \\ Kyle S. Herrman \\ University of Nebraska-Lincoln, Kyle.Herrman@uwsp.edu \\ See next page for additional authors
}

Follow this and additional works at: https://digitalcommons.unl.edu/natrespapers

Part of the Natural Resources and Conservation Commons

Lenters, John D.; Cutrell, Gregory J.; Istanbulluoglu, Erkan; Scott, Durelle T.; Herrman, Kyle S.; and Eisenhauer, Dean E., "Seasonal energy and water balance of a Phragmites australis-dominated wetland in the Republican River basin of south-central Nebraska (USA)" (2011). Papers in Natural Resources. 317. https://digitalcommons.unl.edu/natrespapers/317

This Article is brought to you for free and open access by the Natural Resources, School of at DigitalCommons@University of Nebraska - Lincoln. It has been accepted for inclusion in Papers in Natural Resources by an authorized administrator of DigitalCommons@University of Nebraska - Lincoln. 


\section{Authors}

John D. Lenters, Gregory J. Cutrell, Erkan Istanbulluoglu, Durelle T. Scott, Kyle S. Herrman, and Dean E. Eisenhauer 


\title{
Seasonal energy and water balance of a Phragmites australis-dominated wetland in the Republican River basin of south-central Nebraska (USA)
}

\author{
J. D. Lenters, ${ }^{1}$ G. J. Cutrell, ${ }^{1}$ E. Istanbulluoglu, ${ }^{2}$ D. T. Scott, ${ }^{3}$ \\ K. S. Herrman, ${ }^{4}$ A. Irmak, ${ }^{1,5}$ and D. E. Eisenhauer ${ }^{1,6}$ \\ 1. School of Natural Resources, University of Nebraska-Lincoln, Lincoln, NE 68583, USA \\ 2. Civil and Environmental Engineering, University of Washington, Seattle, WA, USA \\ 3. Department of Biological Systems Engineering, Virginia Tech University, Blacksburg, VA, USA \\ 4. College of Natural Resources, University of Wisconsin-Stevens Point, Stevens Point, WI, USA \\ 5. Department of Civil Engineering, University of Nebraska-Lincoln, Lincoln, NE, USA \\ 6. Biological Systems Engineering Department, University of Nebraska-Lincoln, Lincoln, NE, USA \\ Corresponding author - J. D. Lenters, tel 402 304-0166, fax 402 472-2946, email jlenters2@unl.edu
}

\begin{abstract}
Climate and vegetation strongly influence the water cycle on local to regional scales. A change in the surface energy and water balance, especially in dry climatic regions, can have a significant impact on local water availability and, therefore, water resource management. The purpose of this study is to quantify the energy and water balance of a riparian wetland in a subhumid region of the central US, as well as the role of seasonal climate variability and vegetation phenology. The site is located in the Republican River basin in south-central Nebraska, where decreases in streamflow have been observed in recent decades. In an effort to reduce consumptive water use from evapotranspiration (ET), and thereby reclaim surface water, invasive species such as Phragmites australis have been removed throughout the riparian corridor of the river basin. In this study, we used energy/water balance monitoring stations, a Large Aperture Scintillometer (LAS), and numerous water and soil temperature probes to determine the energy and water balance during the 2009 growing season (April 11-October 3). Sensible heat flux was measured using the LAS, while ET was calculated as a residual of the energy balance (i.e., net radiation minus sensible heat flux and heat storage rates in the canopy, water, and soil). Rigorous quality control and uncertainty analyses were performed, and comparisons were also made with ET rates calculated via the simpler Priestley-Taylor method.

Results of the energy budget analysis indicate that the average ET rate for the wetland during the growing season was $4.4 \mathrm{~mm}_{\text {day }}{ }^{-1}$, with a maximum daily rate of $8.2 \mathrm{~mm} \mathrm{day}^{-1}$ (occurring on June 29). Precipitation during the same 176-day period averaged $2.7 \mathrm{~mm} \mathrm{day}^{-1}$. Net radiation and vegetation phenology were found to be the two largest drivers of seasonal variability in ET. Sensible heat flux was significantly larger than latent heat flux early in the season, when standing vegetation in the wetland was still dry and brown. By late May and early June, however, Bowen ratios had declined well below 0.5 in response to greener and more abundant vegetation, higher transpiration rates, and reduced sensible heat flux. Heat storage rates in the wetland were dominated by changes in water temperature (as compared to soil or canopy heat storage) and comprised a significant portion of the hourly energy balance. On daily mean timescales, changes in the rate of heat storage corresponded to $\sim 13 \%$ of the variability in net radiation, while for the season-long average, the heat storage term was found to be essentially negligible. The Priestley-Taylor equation provided a reasonable estimate of ET during the height of the growing season but significantly overestimated ET during the beginning of the season (since it could not account for large sensible heat fluxes from the dry vegetation). Analysis of the wetland water balance showed seasonal variations in water level that were similar to changes in cumulative water inputs (i.e., precipitation minus ET). Portions of the season when the two curves had differing rates of change indicated periods of net water influx or outflux from other sources (primarily groundwater).
\end{abstract}

Keywords: energy balance, evapotranspiration, water balance, Phragmites australis, large aperture scintillometer, wetland 


\section{Introduction}

\subsection{Background}

The need to improve our understanding of the global and regional water balance is readily apparent, particularly in the presence of increasing population, as well as changes in land use and climate. Current studies of the water balance include efforts to understand how surface water resources such as lakes and rivers are changing as a result of climatic and anthropogenic influences, with implications for drinking water, irrigation, industry, ecosystems, and hydropower (Brekke et al., 2009; Gray and McCabe, 2010; Mujumdar, 2008; Szwed et al., 2010). Surface waters are directly connected with atmospheric processes, but they are also linked to groundwater recharge and aquifers, which provide water for drinking and irrigation. Understanding the effects of climate and land use on surface and groundwater resources requires a close examination of both the energy and water balance of the land-atmosphere system.

In regions of the world such as the US Great Plains, irrigated agriculture and other forms of "consumptive use" play a significant role in the regional water balance. Surface and groundwater supplies have become stressed as agricultural producers strive to increase crop yield in water-limited regions. The Republican River basin, which occupies portions of Colorado, Nebraska, and Kansas (Figure 1), is an example of a semi-arid to subhumid region that has been significantly impacted by the use of surface water and groundwater for irrigation. In response to an extended drought during the 1930s and a devastating flood in 1935, a compact to manage water usage in the Republican River basin among the three states was declared in 1943. In 1999, Nebraska began facing legal challenges from Kansas in association with declines in Republican River streamflow (Kansas Department of Agriculture, 2010). Several studies have investigated the causes of this reduction in streamflow (Szilagyi, 1999, 2001; Burt et al., 2002; Wen and Chen, 2006), and these studies have found that changing climatic influences such as precipitation and temperature cannot explain the decrease in streamflow. Rather, human activities such as crop irrigation, as well as changes in vegetative cover, water conservation practices, and the construction of reservoirs were determined to be the primary drivers. Various modeling and statistical analyses, for example, found a significant relationship between increasing irrigation wells and decreasing streamflow (Burt et al., 2002; Wen and Chen, 2006).
In an effort to increase streamflow in the Republican River and improve stream function and biodiversity, the state of $\mathrm{Ne}-$ braska began removing invasive plant species along the riparian corridors of the Republican and Platte River systems in 2007. The intent of this vegetation removal campaign was at least threefold: (1) decrease consumptive use of water along the river by reducing riparian evapotranspiration (ET), (2) remove invasive species to help restore native vegetation and biodiversity, and (3) remove vegetation along stream channels and bars to improve stream function, ecology, and habitat for birds and other wildlife. Other states have undertaken similar vegetation removal campaigns for similar reasons (e.g., Monteiro et al., 1999; Wilcox and Whillans, 1999; Grothues and Able, 2003; Kiviat, 2006; Virginia DCR, 2007). In Nebraska, the primary plant species targeted for removal (predominantly through spraying of herbicide) were Phragmites australis (common reed), Tamarix (salt cedar), and Elaeagnus angustifolia (Russian olive).

In this study, we examined the consumptive use of water by $P$. australis in a riparian corridor of the Republican River basin. This required an understanding of the surface energy and water balance, particularly the role of latent heat flux (i.e., ET). Previous studies have used various methods and instrumentation to determine the rate of ET for $P$. australis, such as the Bowen Ratio Energy Budget (BREB) method (Smid, 1975; Burba et al., 1999a; Sánchez-C et al., 2004; Peacock and Hess, 2004), a phytometer (Fermor et al., 2001), measurements of sap flow (Moro et al., 2004), and the eddy covariance (EC) method (Zhou and Zhou, 2009). Jia et al. (2009) applied an energy budget model using MODIS satellite data to estimate the rate of ET from $P$. australis over the Yellow River Delta in China. In the current study, we used a Large Aperture Scintillometer (LAS) to determine sensible heat flux, which was then combined with measurements of net radiation and ground heat storage to calculate latent heat flux as a residual of the energy balance. For comparison purposes, we also estimated ET rates using the Priestley-Taylor method, which is a simplified version of the BREB technique. While the EC method is a popular and well-tested methodology for measuring ET, the EC method is not suitable in areas of significant spatial heterogeneity (such as narrow riparian systems with varying vegetation height) and often has problems with energy balance closure (Twine et al., 2000). LAS systems have been tested against EC systems over homogenous and heterogeneous land types and have been found to be a reliable and accurate method for

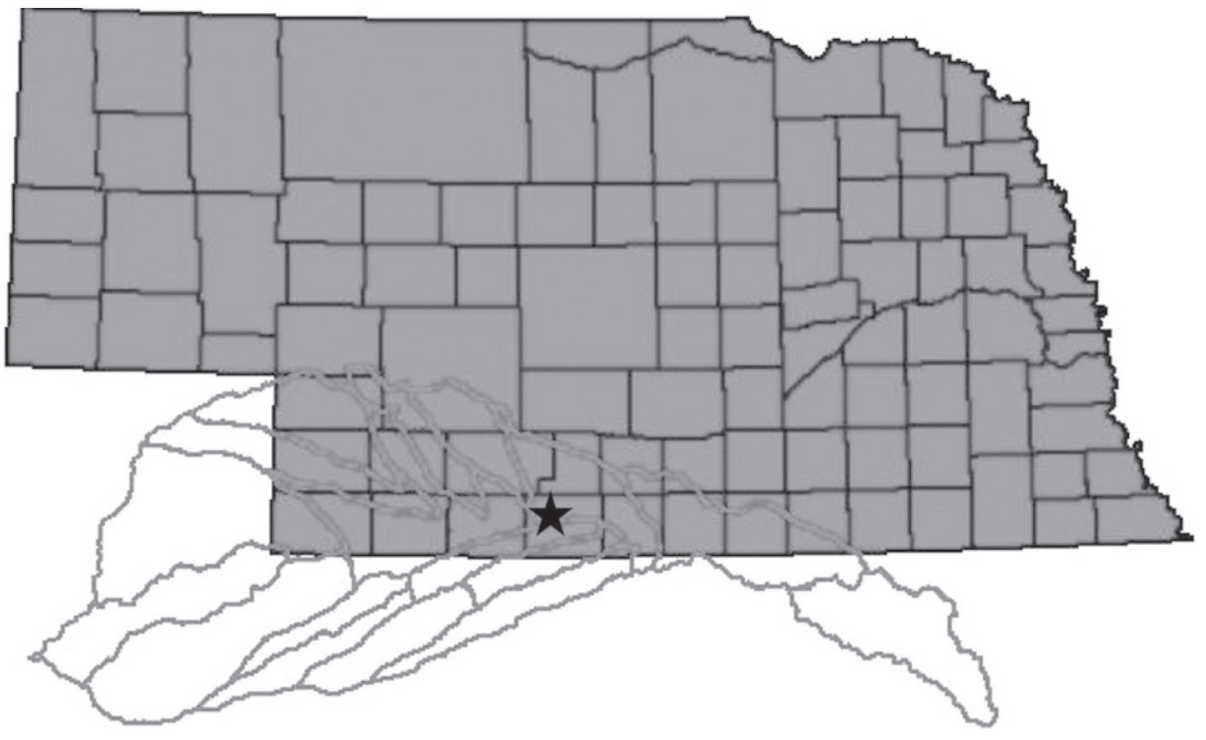

Figure 1. Map showing the wetland study site (star) in southwest Nebraska (shaded) within the Republican River basin. The site latitude and longitude are $40^{\circ} 17.91^{\prime} \mathrm{N}$ and $99^{\circ} 57.90^{\prime} \mathrm{W}$, respectively. 
estimating sensible heat flux and associated ET rates (Chehbouni et al., 2000; Hoedjes et al., 2002; Meijninger et al., 2006; Ezzahar et al., 2007; Kleissl et al., 2008).

The primary goal of this study is to estimate the rate of ET from $P$. australis during the 2009 growing season for a riparian wetland in south-central Nebraska. We are also interested in understanding the relative roles of local meteorology and vegetation phenology in determining ET rates, as well as the diurnal, daily, and seasonal variability in the surface energy and water balance. Although the wetland was sprayed with herbicide in late July of 2009 (to assess the impact of vegetation removal), a clear response to this spraying was not evident until the 2010 growing season. Therefore, the results of the herbicide treatment are not presented here but will instead be discussed in a future comparative study of the 2009 and 2010 seasons. In the next section, we describe the wetland study site and regional climate, followed by a discussion of the methodology (Section 2) and data quality control techniques (Section 3 ). The energy budget results are presented in Section 4, while Section 5 provides a summary of the study and its conclusions.

\subsection{Site description and climatology}

The wetland study site is located in a predominantly agricultural watershed approximately $6 \mathrm{~km}$ west of Arapahoe, Nebraska (Figures 1 \& 2) at an elevation of $664 \mathrm{~m}$ above sea level. The main stem of the Republican River lies roughly $600 \mathrm{~m}$ to the south of the study site. A sparse stand of cottonwood trees surrounds the $36,000-\mathrm{m}^{2}$ wetland, which is approximately $900 \mathrm{~m}$ in length and varies in width from about $5 \mathrm{~m}$ in the western end to $60 \mathrm{~m}$ in the central and eastern portions (Figure 2). The wetland receives a small amount of flowing water from an exposed spring in the far western edge, and water occasionally flows out of the east end of the wetland through an ephemeral stream during periods of high water level. In general, however, the wetland experiences very little surface flow, with most of the "runoff" entering and leaving through groundwater discharge and recharge, respectively. Irrigation occurs in the surrounding fields during portions of the summer, and this can also have an impact on nearby groundwater levels. Water levels in the wetland vary from roughly 0 to $60 \mathrm{~cm}$, and the surface area is occupied by $52 \%$ invasive $P$. australis, 31\% native Typha latifolia (cattail), 8\% native Juncus effusus (common rush), and 9\% open water. The plant community is very tall and dense in most areas, with the $P$. australis grow- ing to approximately $4.2 \mathrm{~m}$ at its maximum height.

Long-term climate data for the region were obtained through the National Climatic Data Center (NCDC) from a National Weather Service Cooperative Observer Program station (COOP station number 250640) in Beaver City, Nebraska, approximately $21 \mathrm{~km}$ southeast of the wetland study site. We examined long-term monthly and annual mean data from this station for the past 30 years (1979-2008) to assess the local climatology, whereas daily and monthly data from 2009 (including measurements from our own wetland meteorological station, discussed in Section 2), were used to examine the atmospheric conditions during 2009.

Most of the western Republican River basin is located in a semi-arid climate, but our study wetland is positioned near the average US boundary between humid and semi-arid climates. Although the most recent 30-year climatology from Beaver City would classify the climate as "humid continental" (according to the Köppen scheme), a more accurate description would be "dry subhumid," since the moisture index of Thornthwaite (1948) lies between -20 and 0 throughout most of central Nebraska. The mean annual maximum, minimum, and average daily temperatures at Beaver City are $20.4{ }^{\circ} \mathrm{C}, 3.3^{\circ} \mathrm{C}$, and $11.9{ }^{\circ} \mathrm{C}$, respectively, and the region receives $605 \mathrm{~mm}$ of annual precipitation, on average. Mean winter snowfall is around $685 \mathrm{~mm}$ (i.e., roughly $68 \mathrm{~mm}$ of water-equivalent snowfall, assuming a 10:1 density ratio). The growing season typically begins in mid-April (after the last spring freeze) and lasts until the first freeze in mid-October. During 2009, the beginning and ending dates occurred around April 11 and October 3, respectively, which we define as the "growing season" for the purposes of this study. Both May and July of 2009 were characterized by well-above-normal precipitation at the wetland site (Cutrell, 2010). June, July, and August were also cooler than normal, as compared to the 30-year climatology. Interestingly, the monthly mean air temperature for July 2009 was also significantly lower at the wetland site than at the Beaver City COOP station, indicating that the wetland may be generally cooler than surrounding land areas in midsummer. We suspect that this is related to the wet conditions and high latent heat flux that exist in the wetland and nearby irrigated fields - a difference that is likely to be most evident during the height of the growing season (i.e., July).

Daily precipitation, water level, air temperature, relative humidity, surface water temperature, and wind speed (all measured at the wetland study site) are shown in Figure 3

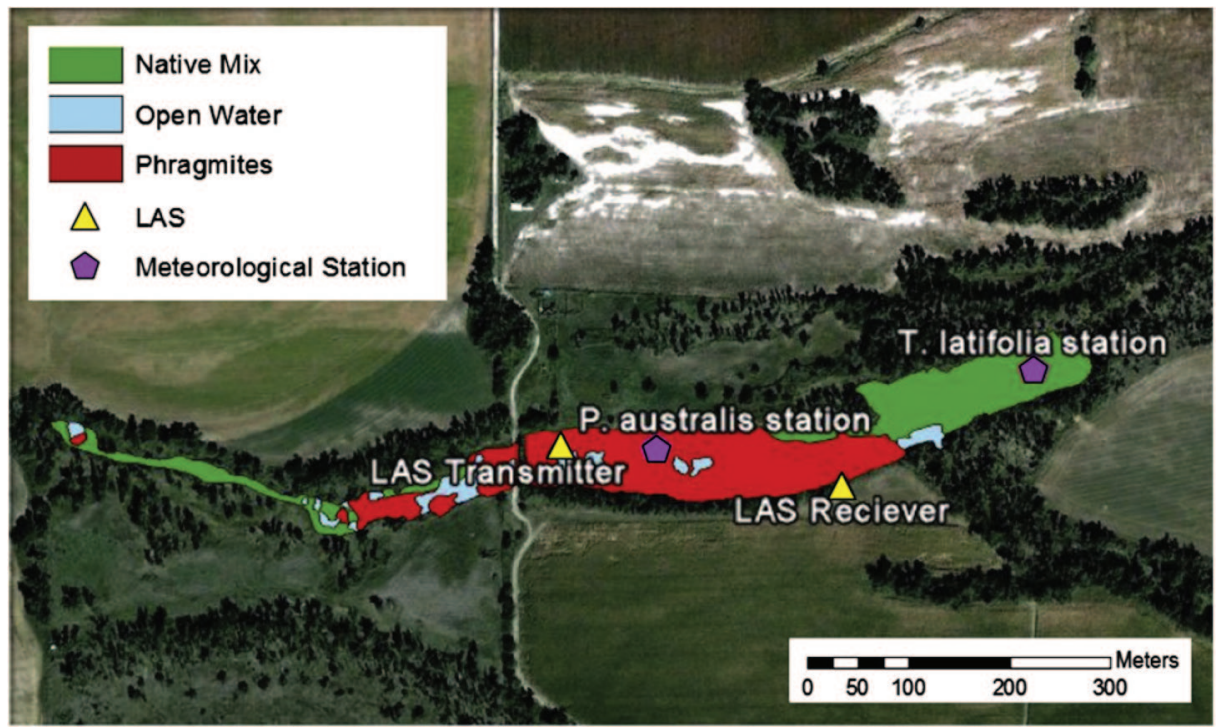

Figure 2. Wetland map showing the land cover classification and locations of the LAS transmitter, LAS receiver, and two meteorological stations (in the P. australis and T. latifolia sections of the wetland). 
for the 2009 growing season. Water levels increased from the beginning of the growing season until late June, after which they steadily decreased until September and then leveled off through the end of the growing season. Daily air temperatures were much more variable than the wetland water temperatures, but they generally oscillated about similar mean values through early June. For the remainder of the year, however, the air temperature was notably warmer than the surface water temperature, particularly from mid-June to mid-August (Figure 3). This is primarily due to the strong shading (and insulating) effect of the tall $P$. australis vegetation on the underlying water column, as well as the high latent heat flux that occurs from the canopy. Groundwater and soil heat flux also exert a cooling influence on the wetland water temperatures during the majority of the growing season.

Daily mean wind speeds at the wetland site were generally strongest during April, May, and late September (Figure $3)$, in association with extratropical storms and frontal activity. Prevailing wind directions in the spring tended to be out of the northwest or southeast (Cutrell, 2010), while winds during June-September were predominantly easterly and much weaker (with occasional northwesterly winds that were stronger, but less common). Even though the anemometer at the wetland station is mounted at a height of over $6 \mathrm{~m}$ above the soil/ water interface (i.e., $\sim 2 \mathrm{~m}$ above the maximum canopy height), it is noteworthy that the daily mean wind speeds are generally quite weak (usually less than $1 \mathrm{~m} \mathrm{~s}^{-1}$ during June-September). Daily mean wind speeds at a nearby High Plains Regional Climate Center (HPRCC) Automated Weather Data Network (AWDN) station in Holdrege, Nebraska, for example, are typically around $3-4 \mathrm{~m} \mathrm{~s}^{-1}$. We attribute the reduction in wind speeds at our wetland site to the "wind shading" effect of the sparse cottonwood trees that surround the wetland, as well as the added surface resistance that occurs in conjunction with the growth of the tall $P$. australis vegetation. Weaker daytime surface mixing, in association with strong evaporative cooling in the wetland and surrounding agricultural fields, may also be responsible for some of the reduced wind speeds. Although these effects at our wetland site result in important differences from other nearby meteorological stations, it is important to note that such characteristics are quite representative of most riparian zones, which are the intended focus of this study.
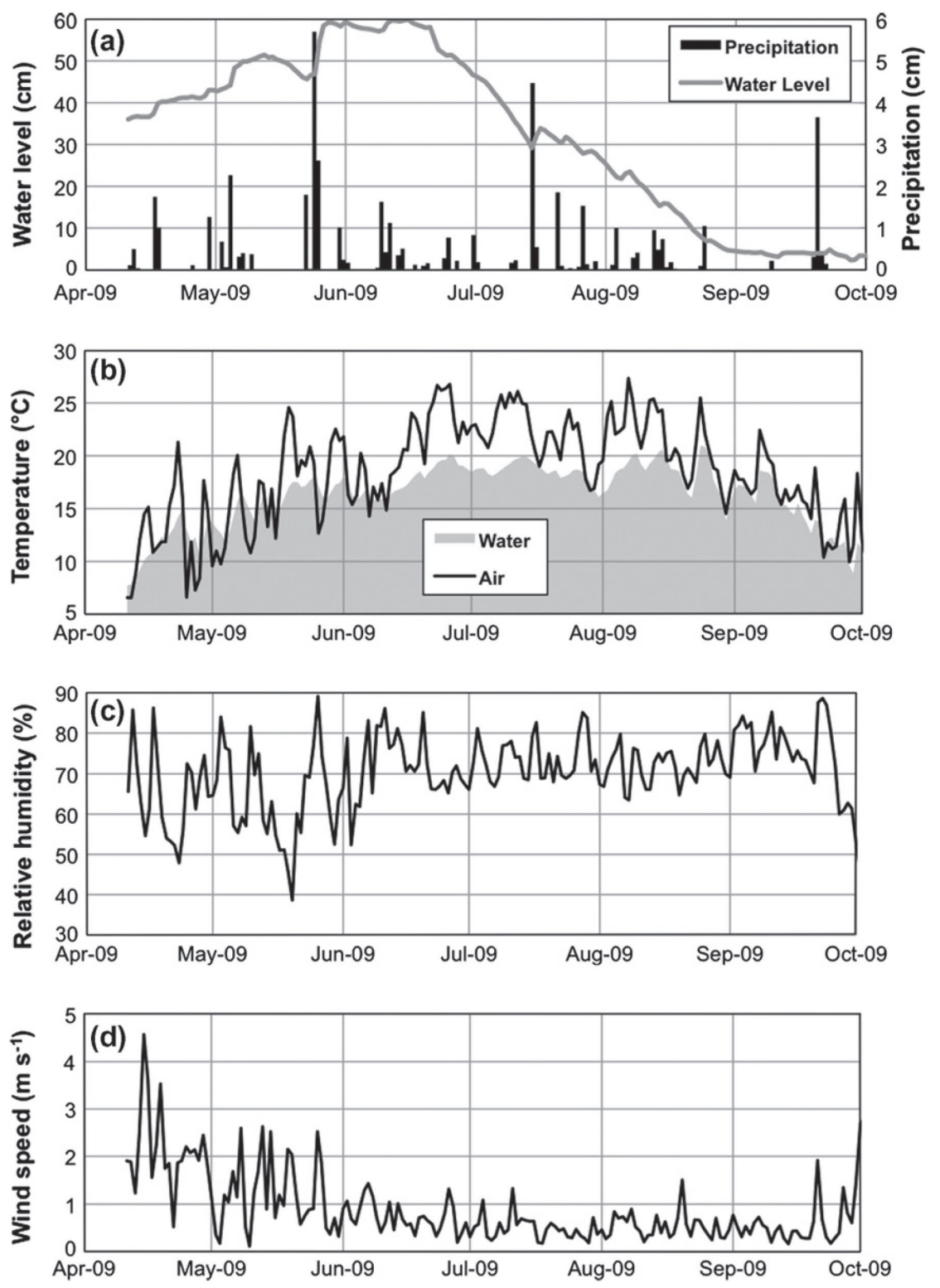

Figure 3. Daily mean (a) precipitation and water level, (b) air temperature and surface water temperature, (c) relative humidity, and d) wind speed, as measured at the $P$. australis meteorological station during the 2009 growing season. 


\section{Methodology}

\subsection{Instrumentation}

A meteorological tower was installed in the invasive $P$. australis portion of the wetland (Figure 2) to monitor the surface energy and water balance, as well as the basic meteorology. The tower is $6.3 \mathrm{~m}$ tall at its maximum height and is located in a dense $P$. australis area roughly $20 \mathrm{~m}$ away from the northern edge of the wetland and $40 \mathrm{~m}$ away from the southern edge. Measurements at the station include incoming solar radiation, ventilated air temperature and relative humidity (at two heights separated by $1.8 \mathrm{~m}$ ), wind speed and direction, barometric pressure, net shortwave and longwave radiation, precipitation rate, and radiometrically derived surface temperature (looking downward at the vegetation and water). A measurement rod and digital camera were also installed to estimate the daily plant height and weather conditions. A second meteorological station was deployed in the east end of the wetland (Figure 2) to make similar measurements, but in a region of native vegetation (primarily $T$. Latifolia); the station also provided backup measurements during times of occasional instrument failure at the primary station. Periodic leaf area index (LAI) measurements of the P. australis were made over the course of the growing season using an LAI-2000 (LI-COR Biosciences; equipment brand names are mentioned for informational purposes only and do not represent an endorsement of the product.). Two sets of continuous water level measurements were obtained in the wetland using a Level TROLL 300 transducer (In-Situ, Inc.) and an SR50A sonic ranging sensor (Campbell Scientific, Inc.). Three pairs of HOBO temperature probes (U23-003 2× External Temperature Data Logger; Onset Computer Corporation) were installed on stakes and driven into the ground to measure the soil and water temperature and heat storage rates at six different depths, each separated by $30 \mathrm{~cm}$. Finally, a KD2 Pro analyzer (Decagon Devices, Inc.) was used to measure the specific heat and thermal conductivity of the soil at various locations in the wetland.

A Kipp \& Zonen LAS system, which consists of a transmitter and receiver, was installed over the $P$. australis to measure sensible heat flux. The LAS (with a $10-\mathrm{cm}$ aperture restrictor) was aligned along a path that placed the meteorological station at roughly the midpoint of the transect (Figure 2), with $251 \mathrm{~m}$ of separation between the transmitter and receiver. The LAS receiver measured fluctuations in beam intensity, which were then recorded at 1-s intervals and averaged to 10-min values using a CR1000 datalogger (Campbell Scientific, Inc.). Computer software (known as "EVATION") was provided by Kipp \& Zonen to calculate sensible heat flux from the 10-min LAS, meteorological, and soil/water temperature data. Data inputs for EVATION include upper and lower air temperature, relative humidity, net radiation, heat storage rate, wind speed, and barometric pressure.

\subsection{Surface energy balance}

In this study, we apply the surface energy balance method, for which the governing equation is

$$
R n-L E-H=\frac{\Delta S}{\Delta t},
$$

where $R n$ is net radiation, $L E$ is latent heat flux, $H$ is sensible heat flux, and $\Delta S / \Delta t$ is the total rate of heat storage in the "ground" (i.e., vegetation canopy, surface water, and soil). The sign convention in Equation (1) is such that positive $R n$ and $\Delta S / \Delta t$ denote heat fluxes or storage "into the ground," while positive $L E$ and $H$ denote cooling of the surface (i.e., heat fluxes "out of the ground"). Equation (1) can be rearranged to solve for the latent heat flux:

$$
L E=\left(R n-\frac{\Delta S}{\Delta t}\right)-H,
$$

which results in estimates of $L E$, with $H$ determined independently through the LAS-based measurements of sensible heat flux. The rate of heat storage in the wetland is measured using multiple temperature sensors at various heights throughout the canopy, water, and soil columns. Although heat storage in the vegetation canopy is often ignored, it is estimated here for completeness, since $P$. australis is very tall and dense. The total rate of heat storage in the wetland $(\Delta S / \Delta t)$ is then calculated as the sum of the heat storage from four separate layers: (1) the vegetation/air canopy (with variable vegetation height), (2) the water layer (also of variable height), (3) the upper $60-\mathrm{cm}$ soil layer, and (4) deep soil heat flux beneath the 60 $\mathrm{cm}$ layer. Each layer contains 1-2 temperature sensors, with the water layer also having a floating sensor at the water surface. As noted earlier, the soil temperature sensors are separated by a fixed $30-\mathrm{cm}$ interval, while the deep soil heat flux is calculated from the temperature gradient across the bottom two sensors.

Mathematically, the total rate of heat storage in the wetland can be written as

$$
\frac{\Delta S}{\Delta t}=\left(\frac{\Delta S}{\Delta t}\right)_{\text {canopy }}+\left(\frac{\Delta S}{\Delta t}\right)_{\text {water }}+\left(\frac{\Delta S}{\Delta t}\right)_{\text {upper soil }}+\left(\frac{\Delta S}{\Delta t}\right)_{\text {deep soil }},
$$

where

$$
\begin{aligned}
& \left(\frac{\Delta S}{\Delta t}\right)_{\text {canopy }}=\left(\rho_{a} \cdot h_{a} \cdot C p_{a} \cdot \frac{\Delta T_{a}}{\Delta t}\right)+\left(m_{\text {veg }} \cdot C p_{\text {veg }} \cdot \frac{\Delta T_{\text {veg }}}{\Delta t}\right), \\
& \left(\frac{\Delta S}{\Delta t}\right)_{\text {water }}=\rho_{w} \cdot h_{w} \cdot C p_{w} \cdot \frac{\left\langle\Delta T_{w}\right\rangle}{\Delta t}, \\
& \left(\frac{\Delta S}{\Delta t}\right)_{\text {upper soil }}=h_{S} \cdot V H C_{S} \cdot \frac{\left\langle\Delta T_{S}\right\rangle}{\Delta t},
\end{aligned}
$$

and

$$
\left(\frac{\Delta S}{\Delta t}\right)_{\text {deep soil }}=K_{S} \cdot\left(\frac{\Delta T_{S 45 \mathrm{~cm}-75 \mathrm{~cm}}}{\Delta Z_{S 45 \mathrm{~cm}-75 \mathrm{~cm}}}\right) .
$$

The subscripts $s, w, a$, and veg refer to soil, water, air, and vegetation parameters, respectively, while $\rho\left(\mathrm{kg} \mathrm{m}^{-3}\right)$ is density, $h$ $(\mathrm{m})$ is the thickness of the layer, $m_{v e g}$ is the fresh vegetation biomass per unit area $\left(\mathrm{kg} \mathrm{m}^{-2}\right), V H C\left(\mathrm{~J} \mathrm{~m}^{-3}{ }^{\circ} \mathrm{C}^{-1}\right)$ is the volumetric heat capacity, $C p\left(\mathrm{~J} \mathrm{~kg}^{-1}{ }^{\circ} \mathrm{C}^{-1}\right)$ is the specific heat, $\mathrm{K}\left(\mathrm{W} \mathrm{m}{ }^{-1}{ }^{\circ} \mathrm{C}^{-1}\right)$ is thermal conductivity, $\Delta T / \Delta t\left({ }^{\circ} \mathrm{C} \mathrm{s}^{-1}\right)$ is the temporal rate of change in temperature, $\Delta T / \Delta z\left({ }^{\circ} \mathrm{C} \mathrm{m}^{-1}\right)$ is the vertical temperature gradient, and brackets indicate a depth-weighted vertical average. $V H C_{s}$ and $K_{s}$ were determined from the average of five measurements taken at various locations near the meteorological tower. The measurements were made in the soil near the water/soil interface and are assumed to be representative of the deeper soil layers as well (likely a reasonable assumption, given the saturated conditions in the wetland). The mean (and standard deviation) were found to be $3435( \pm 298) \mathrm{J} \mathrm{kg}^{-1}{ }^{\circ} \mathrm{C}^{-1}$ and $0.995( \pm 0.219) \mathrm{W} \mathrm{m}^{-1}{ }^{\circ} \mathrm{C}^{-1}$ for $V H C_{s}$ and $K_{s^{\prime}}$ respectively. Although the specific heat of $P$. australis was not measured directly, a value of $2700 \mathrm{~J} \mathrm{~kg}^{-1}{ }^{\circ} \mathrm{C}^{-1}$ was used for fresh vegetation (Thom, 1975; Moore and Fisch, 1986; Chen et al., 2007; Higuchi et al., 2007). Maximum fresh biomass was estimated from measurements of maximum dry biomass (see Section 4.1) and an assumed average water content of $86 \%$ at full growth (Smart and Bingham, 1974; Pelleschi et al., 1997). Daily LAI estimates (based on a polynomial fit of the periodic sampling) were used to represent the $P$. australis phenology and scale the maximum fresh biomass accordingly throughout the growing season (i.e., to determine the actual fresh biomass as a function of time). 


\subsection{Large Aperture Scintillometry}

As noted earlier, we used an LAS system to directly estimate the amount of sensible heat flux from the wetland. These fluxes are derived from measurements of atmospheric scintillations associated with changes in the index of refraction of air due to turbulent fluctuations in air temperature and water vapor content. LAS theory has been discussed in depth elsewhere and can be found in numerous publications (e.g., Wyngaard and Izumi, 1971; Wesely, 1976; Hoedjes et al., 2002; Hartogensis et al., 2003; Kipp and Zonen, 2007; Kleissl et al., 2008). Details specific to this study are also discussed in $\mathrm{Cu}-$ trell (2010). It is important to note that saturation of the LAS can occur on occasion, such as instances where $H$ becomes so strong that the measured scintillations level off and eventually decrease (Kohsiek et al., 2006). This phenomenon has been investigated through experimentation (Clifford et al., 1974; Wang et al., 1978), as well as tested in the field by Kohsiek et al. (2006). Despite the significant height of the P. australis vegetation at our field site during the growing season, we found no evidence of LAS saturation. This suggests that the height and spacing of the LAS transmitter and receiver were appropriate for the conditions at our site.

\subsection{Priestley-Taylor method}

For comparison with the LAS-derived energy balance, we also estimated ET rates using the simpler Priestley-Taylor (P-T) method (Priestley and Taylor, 1972). As noted earlier, the P-T formula is based on simplifications to the BREB method - primarily by approximating the Bowen ratio using the slope of the saturation vapor pressure curve (which is dependent only on temperature). The method is typically used to estimate potential evapotranspiration (PET) over a saturated surface under conditions of minimal advection, which generally tends to be the case at our wetland site during the height of the growing season (in part because of the surrounding irrigated cropland; Figure 2). The advantage of the P-T equation over the BREB method is that it does not require direct estimates of the Bowen ratio (which necessitates precision temperature and humidity measurements at two heights). We calculated PET rates on a daily basis (as a heat flux, in $\mathrm{W} \mathrm{m}^{-2}$ ) using the standard P-T relationship:

$$
P E T=\alpha \cdot\left[\frac{s}{(s+y)}\right] \cdot\left(R n-\frac{\Delta S}{\Delta t}\right),
$$

where $\alpha=1.26, s\left(\mathrm{kPa}^{\circ} \mathrm{C}^{-1}\right)$ is the slope of saturation vapor pressure curve, and $\gamma\left(\mathrm{kPa}^{\circ} \mathrm{C}^{-1}\right)$ is the psychrometric constant. The "standard" P-T coefficient of $\alpha=1.26$ (used in the present study) compares well with the average value of 1.3 found by Burba et al. (1999a) for early and peak growth stages of a $P$. australis wetland in Nebraska. It has also been found that 1- to 10-day averages of the P-T relationship provide reasonable estimates of ET over shallow lakes and ponds when compared to the energy balance method (Stewart and Rouse, 1976; De Bruin and Keijman, 1979; Rosenberry et al., 2004).

\subsection{Water balance}

Water balance measurements are used in this study to provide additional verification of the calculated ET rates through comparison with changes in water level. The water budget calculations also allow us to assess the relative significance of other water balance components such as precipitation and groundwater discharge/recharge. Similar to the energy balance (Equation (1)), the water balance can be expressed as

$$
P-E T+G W_{n e t}+Q_{n e t}=\frac{\Delta L}{\Delta t}
$$

where $P\left(\mathrm{~mm} \mathrm{day}^{-1}\right)$ is precipitation rate, $G W_{\text {net }}\left(\mathrm{mm} \mathrm{day}^{-1}\right)$ is the net flux of groundwater into/out of the wetland (per unit surface area), $Q_{\text {net }}\left(\mathrm{mm} \mathrm{day}^{-1}\right)$ is the net flow of surface water, and $\Delta L / \Delta t\left(\mathrm{~mm} \mathrm{day}^{-1}\right)$ is the rate of change in the wetland water level. As noted earlier, the study site has very limited amounts of direct surface runoff into or out of the wetland, so we assume $Q_{\text {net }}$ to be negligible relative to other terms in Equation (9). We also assume a flat wetland geometry, since incorporation of water surface area into Equation (9) (using a more complicated wetland bathymetry) was not found to have a significant effect on the final results.

Integrating Equation (9) over time and ignoring $Q_{\text {net }}$ allows us to solve for water level:

$$
L_{t}=L_{0}+\sum_{t}(P-E T)+\sum_{t} G W_{n e t},
$$

where $L_{t}(\mathrm{~mm})$ is water level at time $t, L_{0}(\mathrm{~mm})$ is the initial water level (i.e., a constant), and the summation symbol refers to cumulative values through time. From Equation (10), it is evident that graphs of cumulative $P-E T$ can be compared with water level to assess the overall influence of net groundwater flux through time. Similarly, during periods of limited precipitation and groundwater discharge/recharge, the observed drop in water level, $L_{t}-L_{0}$, should match the cumulative loss of water through ET. In this way, then, Equation (10) can be used to provide additional verification of energy budget-derived ET estimates, as well as an assessment of the potential influence of groundwater.

\section{Data quality and uncertainty}

\subsection{General instrument uncertainty}

Given the many factors involved in calculating ET from the energy budget method, particularly as a residual, it is important to assess the reliability of the various data sources, to quantify the uncertainty in each of these sources, and to estimate the impact of the cumulative uncertainties on the final ET calculations. Table 1 lists the manufacturer-stated maximum uncertainties for many of the measured variables, but additional sources of error need to be considered as well particularly those that relate to the calculation of sensible heat flux. For example, LAS-derived sensible heat flux values are sensitive to the height of the LAS above the canopy, which is also an input parameter in the data processing software, EVATION. Since this height varies with the height of the vegetation, it is important to assess the precision with which the plant height must be specified, as well as how often it should be updated in the calculations over the course of the growing season. In this section, we examine these and other sources of uncertainty, as well as the net impact

Table 1. Estimated maximum measurement uncertainties (based on manufacturers' instrument specifications)

\begin{tabular}{ll}
\hline Measurement & Maximum uncertainty \\
\hline Wind speed & $\pm 1 \%$ (at least $0.3 \mathrm{~m} \mathrm{~s}^{-1}$ ) \\
Wind direction & $\pm 3^{\circ}$ \\
Upper air temperature/RH & $\pm 0.01^{\circ} \mathrm{C}, \pm 4 \% \mathrm{RH}$ \\
Lower air temperature/RH & $\pm 0.01^{\circ} \mathrm{C}, \pm 4 \% \mathrm{RH}$ \\
Canopy air temperature/RH & $\pm 0.4^{\circ} \mathrm{C}, \pm 3 \% \mathrm{RH}$ \\
Net radiation & $\pm<10 \%$ daily total \\
Radiometric surface temperature & $\pm 0.5^{\circ} \mathrm{C}$ \\
Incoming solar radiation & $\pm<10 \%$ daily total \\
Barometric pressure & $\pm 2.5 \mathrm{hPa}$ \\
Rainfall rate & $\pm 1 \%$ (up to $1 \mathrm{~cm} / \mathrm{hr}$ ) \\
Soil/ water temperature & $\pm 0.1^{\circ} \mathrm{C}$ (wetland mean) \\
Soil specific heat & $\pm 5 \%$ \\
Soil thermal conductivity & $\pm 5 \%$ \\
\hline
\end{tabular}


of all potential error sources on the resulting energy balance calculations. We also discuss the various quality control (QC) methods that are used to identify, remove, and gap-fill certain erroneous data points - not only for the sensible heat flux, but for other variables as well.

\subsection{Air temperature gap filling}

A comparison with measurements from the second meteorological station (within the T. latifolia section of the wetland; Figure 2) revealed a period of erroneous air temperature measurements from the upper sensor at the $P$. australis station from June 14 to July 23. Since the temperature gradient between the upper and lower sensor is needed for the calculation of sensible heat flux, an accurate gap-filling method was needed. It was found that net radiation had the best relationship with the vertical temperature gradient $\left(r^{2}=0.66\right)$, and a 2nd-order polynomial fit was used to fill in the data gap ( $\mathrm{Cu}$ trell, 2010). To check the accuracy of the gap-filling algorithm, the observed and "derived" vertical temperature gradients were compared during periods of good data $(1$ month prior and after the data gap). It was found that the root mean square (RMS) difference between the measured and estimated temperature gradient was approximately $0.80{ }^{\circ} \mathrm{C}$. Typical vertical temperature gradients range from about -5 to $+3^{\circ} \mathrm{C}$, so the gap-filling procedure leads to an estimation error of approximately $27 \%$ or less. More importantly, given that the LAS sensible heat flux calculations require only the sign of the vertical temperature gradient (rather than the magnitude), we are confident that this gap-filling procedure is effective at simply identifying stable vs. unstable atmospheric conditions. Furthermore, the data gap occurs during the height of the growing season, when sensible heat flux values (and uncertainties) are generally quite low.

\subsection{LAS quality control}

To examine the sensitivity of the LAS-derived sensible heat flux to the specified plant height, EVATION was run through multiple iterations over the course of the growing season, changing only the input plant height (by 0.5-m increments from 1.5 to $4.5 \mathrm{~m}$ ). Sensible heat flux values from the various runs were compared with those using a plant height of $3.0 \mathrm{~m}$. It was determined that an uncertainty of $\pm 1.5 \mathrm{~m}$ in the input plant height results in an RMS difference of approximately $15.8 \mathrm{~W} \mathrm{~m}^{-2}$ in the sensible heat flux values $(48 \%$ of the seasonal mean value), whereas an uncertainty of $\pm 0.5 \mathrm{~m}$ reduces the RMS difference to $5.1 \mathrm{~W} \mathrm{~m}^{-2}$ (roughly a $15 \%$ error). Considering that the measured height of the $P$. australis varied considerably over the course of the growing season (1.9-4.2 m), we concluded that it is necessary to accurately account for the change in plant height when computing sensible heat flux. To accomplish this, we utilized output from five EVATION runs that assumed fixed plant heights of 2.0, 2.5, 3.0, 3.5, and $4.0 \mathrm{~m}$ for the entirety of the growing season. Observed daily values of plant height (Figure 4; some through linear interpolation) were then used to determine which EVATION output should be used, based on the "simulated" plant height that was closest to the observed value (to the nearest $0.5 \mathrm{~m}$ ). Given that the largest discrepancy that can occur between assumed and observed plant height is $0.25 \mathrm{~m}$, we estimate that the RMS uncertainty in $H$ due to plant height is less than $8 \%$ (i.e., roughly $15 \%$ error at the $95 \%$ confidence level).

After accounting for the changes in vegetation height, the LAS-derived sensible heat flux values were examined to identify any significant anomalies or outliers. We observed a systematic tendency for erroneously high sensible heat flux values during the early morning and late evening hours, around the times of sunrise and sunset. The sensible heat flux was also much more variable during these hours of the day, and the anomalous values typically lasted for about 1-3 h. An examination of ancillary meteorological variables and other components of the energy balance offered no reason to believe that the observed spikes in sensible heat flux were either physically plausible or real. Rather, we suspect that the erroneous values are simply an artifact of the strong changes in atmospheric stability and index of refraction that often occur around sunrise and sunset. As such, an algorithm was developed to identify and remove these morning and evening spikes in sensible heat flux. (A detailed discussion of the LAS QC algorithms can be found in Cutrell (2010).) After removing the erroneous data points through two QC methods (which identified errors during $7 \%$ of the total time period, or $23 \%$ of the sunrise/sunset periods), we examined the final mean diurnal cycle of the growing season sensible heat flux and found that the anomalous sunrise and sunset spikes had been effectively removed.

In order to fill in the short data gaps that were created by this QC procedure, regressions between the sensible heat flux values and other ancillary atmospheric variables were created (using data from the remaining 93\% that had no data gaps). For unstable periods (lower air temperature $>$ upper air temperature), it was found that the product of net radiation and wind speed (i.e., $R n * U$ ) produced the best overall regression with the 10 -min sensible heat flux values. This relationship was split into periods of "daytime" (i.e., $R n$ * $U>0$ ) and "nighttime" $(R n * U<0)$ in order to create two separate regressions (since $H$ and $R n * U$ are positively correlated during daytime unstable conditions, but negatively correlated during nighttime unstable conditions). The daytime regression was

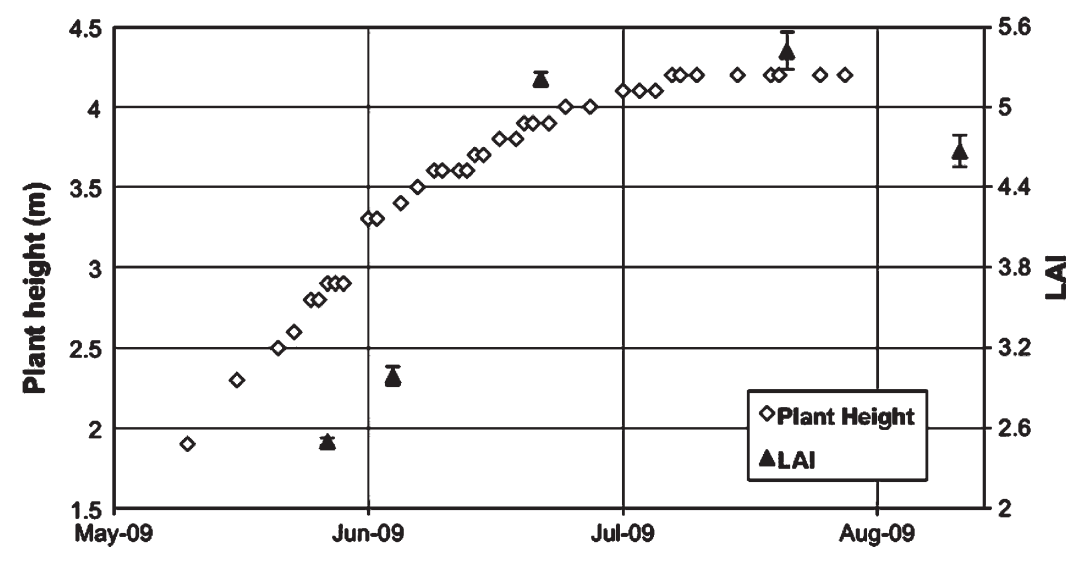

Figure 4. P. australis observed plant height (open diamonds) and LAI (black triangles) during the 2009 growing season. Error bars for LAI indicate the standard deviation of measured values. 
further divided into two seasonal periods (April; May-October) to account for significantly higher sensible heat fluxes during the month of April. The correlation coefficient $(r)$ for the daytime regression between $H$ and $R n$ * $U$ ranged from 0.72 for May-October to 0.86 for April, while the $r$-value for nighttime was found to be -0.52 . Finally, for stable periods (which occurred primarily at night), it was found that a simple regression with wind speed provided the best approximation for sensible heat flux $(r=-0.72)$, and so this relationship was used to fill data gaps during stable periods.

\subsection{LAS-EC comparison}

Prior to deploying the LAS and meteorological station at our wetland site in the Republican River basin, a short deployment was initiated at Mead, Nebraska in the spring of 2008 at an AmeriFlux Network site maintained by researchers at the University of Nebraska (Suyker and Verma, 2010). This site has been collecting EC and energy balance measurements in managed ecosystems (e.g., rainfed and irrigated maize and soybean) for many years, and we used this opportunity to undertake a comparison between the LAS- and EC-derived sensible heat fluxes (and other energy balance components). This information was then used to provide approximate error bounds for the LAS sensible heat flux measurements at the wetland site. Previous comparisons of EC and LAS methods by other researchers have suggested that LAS-derived sensible heat flux values may be systematically higher than those determined from EC measurements, in some cases by up to $21 \%$ (e.g., Randow et al., 2008; Kleissl et al., 2008). It is important to note, however, that EC systems often suffer from a lack of energy balance closure (Wilson et al., 2002; Twine et al., 2000), and this could partially explain the observed differences between LAS and EC measurements of sensible heat flux. At the Mead AmeriFlux site, for example, a regression of $H+L E$ versus total available energy $\left(R_{n}-\Delta S / \Delta t\right)$ shows a mean slope of $0.88 \pm 0.04$ over a multi-year period (Suyker and Verma, 2010). This indicates that net surface heat fluxes at this site are generally underestimated by $\sim 12 \%$ (assuming, of course, that uncertainties in net radiation and ground heat storage are small).

Data collected at the Mead, Nebraska site were compared over a 34-day period (March 20-April 23, 2008) and included hourly mean values of radiative, sensible, latent, and soil heat flux (the latter being measured with two Hukseflux heat flux plates, as well as soil temperature sensors in the top soil layer). Both measurement systems were mounted on towers or tripods above a large, homogenous, open field (rainfed maize/ soybean rotation) with sufficient (and similar) fetch. Less significant energy balance components were ignored during this pre-growing season period (such as heat storage in the canopy, as well as energy used in photosynthesis). A linear regression of the EC-derived hourly sensible heat fluxes vs. the LAS measurements (not shown) revealed very good temporal correspondence $\left(r^{2}=0.96\right)$. However, a mean bias was present, such that the EC-derived sensible heat fluxes were, on average, $\sim 28 \%$ lower than the LAS measurements (based on the slope of the linear regression). Similarly, EC-derived latent heat flux measurements were $\sim 29 \%$ lower (with $r^{2}=0.61$ ) than those calculated as a residual of the LAS-based energy balance. Due to lower EC measurements of both $H$ and $L E$ (compared to the LAS), the Bowen ratio $(B=H / L E)$ for the 34-day period differed by only $6 \%$ between the two measurement techniques ( $B=1.57$ and 1.67 for the EC and LAS methods, respectively). The high Bowen ratios are indicative of the dry field conditions at this time of year and are similar to those that were eventually measured in 2009 (at the wetland field site) prior to the main P. australis growing season (i.e., in April and early May).
Altogether, the above results suggest either a high bias in the LAS-based estimates of $H$ (as well as the energy budget-derived $L E$ ) and/or a low bias in the EC measurements. It is important to note that the two systems showed very good agreement in both net radiation $\left(r^{2}=0.99\right.$; regression slope $\left.=0.95\right)$ and available energy $\left(r^{2}=0.99\right.$; regression slope $\left.=0.99\right)$. This suggests that the above bias is most likely related to problems with energy balance closure in the EC measurements, particularly given the similar Bowen ratios. Indeed, a regression of EC-derived hourly $H+L E$ vs. available energy (not shown) yields a slope of $0.76\left(r^{2}=0.96\right)$, implying a residual in the energy balance that is $\sim 24 \%$ of the available energy (i.e., considerably higher than the $\sim 12 \%$ that is typical for this site; Suyker and Verma (2010)). Given this information, we applied an adjustment to the EC measurements by apportioning the residual between the sensible and latent heat fluxes according to the EC-measured Bowen ratio (which is assumed to be correct), in order to force energy balance closure (similar to the method of Twine et al. (2000)). This adjustment resulted in EC-derived sensible heat flux values that were, on average, only $7 \%$ less than the LAS-derived values (i.e., a significant improvement over the previous $28 \%$ bias, and with the same $r^{2}$ value). Adjusted $L E$ values also showed improvement ( $\sim 4$ difference; $\left.r^{2}=0.65\right)$. Based on the results of these "corrected" EC estimates, we concluded that the LAS system provides reasonably accurate estimates of sensible heat flux (i.e., likely within $\sim 10-$ $15 \%$ of the actual value).

Given the relatively short "validation" period ( 1-month) and generally favorable comparison of the two methods (after EC adjustment), we felt that no "bias correction" was needed for the LAS-derived sensible heat flux values that were subsequently measured at the wetland field site. However, in order to provide maximum error bounds for the sensible heat flux estimates, we assumed two "end-member" scenarios based on results from the 34-day comparison period. The first "lowerbound" scenario reduces all LAS $H$ values by $28 \%$ in order to approximate the raw EC sensible heat flux that was measured during the comparison period. To determine the "upper-bound" scenario, we simply added the residual in the EC energy balance entirely to $H$ (rather than apportioning it between $H$ and $L E$ according to the Bowen ratio). This resulted in $\mathrm{H}$ estimates that were $\sim 1 \%$ higher than the LAS measurements. Thus, the final range of uncertainty applied to the LAS sensible heat flux was $0.72 \mathrm{H}-1.01 \mathrm{H}$, with an "expected value" of $1.0 \mathrm{H}$ (i.e., the $7 \%$ difference noted above is neglected, given the uncertainties in both methods). In other words, while noting that the LAS-derived sensible heat fluxes lie within the bounds of uncertainty in the EC method, we recognize that any errors in $H$ are likely to be biased high, rather than low (similar to what other LAS-EC comparison studies have shown). The estimated uncertainty range of $\sim 29 \%$ is also consistent with the earlier calculations of maximum potential error due to variations in plant height $( \pm 15 \%)$.

\subsection{Cumulative error estimates for ET}

The final error bounds for ET were calculated by adding uncertainties from the various energy balance components in quadrature, which assumes that the errors are random and independent. This includes uncertainties in $\Delta S / \Delta t, R n$, and $H$. Since the water column constitutes the majority of the wetland heat storage term (Equations (3-(7)), errors associated with the soil and canopy components were not explicitly calculated. Rather, uncertainties in the water column temperature measurements were simply scaled up to account for additional potential sources of error (i.e., related to soil and canopy heat storage, spatial extrapolation, etc.).

The $\mathrm{HOBO}$ temperature sensors (described in Section 2.1) measure changes in temperature with a precision of $0.03{ }^{\circ} \mathrm{C}$ 
(which reduces to approximately $0.01{ }^{\circ} \mathrm{C}$ when averaged across multiple sensors on a single probe). Rosenberry et al. (1993) have shown that - for a small lake in northern Minnesota - the use of a single water temperature profile to determine the lake heat storage term results in minimal errors in estimated lake evaporation (on bi-weekly and longer timescales). While this may also be true for our site, spatial variations in water depth, soil thermal properties, and vegetation cover have the potential to increase this uncertainty considerably, particularly for short timescales (daily, hourly, etc.). Therefore, to be conservative, we increased the uncertainty in the mean wetland water temperature by a (somewhat arbitrary) factor of 10 to account for the use of only a single temperature probe (as well as the neglected errors in the soil and canopy heat storage terms). This raises the overall temperature uncertainty to approximately $0.1^{\circ} \mathrm{C}$, resulting in a maximum error in the hourly heat storage rate of $\pm 40.7 \mathrm{~W} \mathrm{~m} \mathrm{~m}^{-2}$ (based on Equation (5), using a mean water depth of $0.35 \mathrm{~m}$, density of $998.9 \mathrm{~kg} \mathrm{~m}^{-3}$, and specific heat of $4186 \mathrm{~J} \mathrm{~kg}^{-1}{ }^{\circ} \mathrm{C}^{-1}$ ). As the temporal averaging period, $\Delta t$, increases to daily and 5-day timescales (see Equation (5)), the uncertainty in the wetland heat storage rate becomes considerably smaller - namely $\pm 1.7 \mathrm{~W} \mathrm{~m}^{-2}$ (daily) and $\pm 0.34 \mathrm{~W} \mathrm{~m}^{-2}$ (5-day).

Taking into account all potential sources of error ( $R n$, $\Delta S / \Delta t$, and $H$ ), we find that the RMS uncertainty in hourly and daily $L E$ is approximately $+53.7 /-50.2 \mathrm{~W} \mathrm{~m}^{-2}$ and $+21.6 /-17.1 \mathrm{~W} \mathrm{~m}^{-2}$, respectively (where the $+/-$ indicate upper/lower bounds). This implies a percent uncertainty of roughly $24 \%$ (hourly) and $14 \%$ (daily) relative to the seasonlong RMS $L E$ values (i.e., RMS hourly $L E=218 \mathrm{~W} \mathrm{~m}^{-2}$, and RMS daily $L E=139 \mathrm{~W} \mathrm{~m}^{-2}$ ). The mean $L E$ for the entire growing season is $124 \mathrm{~W} \mathrm{~m}^{-2}$, which - unlike the RMS calculations - includes negative values in the averaging process (mostly at night and early in the season). Subsequent figures that show error bars for the latent heat flux are based on the above uncertainty analysis (calculated individually for each hour, day, etc.). 5-day running means are also used in numerous instances to highlight seasonal variability (rather than hourly or daily), as well as to minimize uncertainties associated with the heat storage term. Depending on the timescale of interest and ambient climatic conditions, the actual error bounds for $L E$ on a given day (or hour) can be considerably higher or lower than the "typical" values of $24 \%$ and $14 \%$ noted above.

\section{Results}

\subsection{Vegetation height, LAI, and biomass}

After the winter of 2008/2009, a significant amount of dead $P$. australis biomass remained standing at the wetland field site. Most of this biomass was derived from the previous growing season (2008), although some could have lingered from previous years as well. New, green shoots of $P$. australis began to emerge from the wetland around April 20, 2009 (i.e., approximately 9 days after the last spring freeze) and reached a maximum height of $4.2 \mathrm{~m}$ by early July (Figure 4). In addition to plant height, LAI measurements were made five times during the growing season along a marked transect through the $P$. australis (nine samples along each transect). The LAI measurements represent a bulk LAI for both dead and living biomass (as well as both stems and leaves). The 95\% confidence level for the various 9-sample average LAI measurements ranged from $3 \%$ to $6 \%$ of the mean value. Similar to plant height, the LAI increased over the course of the growing season from a minimum of 2.5 on May 27 (the date of first measurement) to a maximum of 5.4 on July 22 (Figure 4).

As part of Nebraska's statewide removal program, the $P$. australis was treated with an herbicide mixture of Roundup ${ }^{\circledR}$ and Habitat ${ }^{\circledR}$ via helicopter on July 22, 2009. From visual observations and energy balance measurements, the $P$. australis ap- peared to be minimally affected in the weeks immediately following treatment (i.e., complete die-off was not observed until the subsequent 2010 growing season). The LAI declined slightly to a value of 4.5 on August 6, although the decline could have simply been associated with natural senescence. At the end of the season, biomass samples from four subplots within the wetland (totaling $1.0 \mathrm{~m}^{2}$ in area) were collected, dried, and weighed, yielding an average dry biomass of $5018 \mathrm{~g} \mathrm{~m}^{-2}$. As noted earlier, this value was used in the estimation of the rate of heat storage in the vegetation canopy (see Section 2.2).

\subsection{Surface radiation balance}

Radiative heat fluxes at the Earth's surface are important drivers of the land surface energy balance. Figure 5 shows 5 -day running mean values of incoming shortwave radiation $\left(S W_{i n}\right)$, incoming longwave radiation $\left(L W_{i n}\right)$, net longwave radiation $\left(L W_{n e t}=L W_{i n}-L W_{\text {out }}\right)$, and net all-wave radiation $\left(R n=S W_{\text {in }}-S W_{\text {out }}+L W_{\text {net }}\right) . S W_{\text {in }}$ shows the largest variation, ranging from a 5-day minimum of $103 \mathrm{~W} \mathrm{~m}^{-2}$ on September 23 to a 5-day maximum of $353 \mathrm{~W} \mathrm{~m}^{-2}$ on May 30. These variations in solar radiation are related to seasonal changes in sun angle and daylength, as well as changes in cloud cover (Figure 6) that occurred in association with extratropical cyclones and fronts (and/or summertime convection). Generally, the month of June would be expected to receive more incoming solar radiation than May, due to the higher sun angle during that time. But significant cloud cover in June of 2009 resulted in lower $S W_{i n}$ than during May, July, and even August (Table 2). As illustrated in Figure $5, L W_{i n}$ largely reflects the seasonal variation in air temperature within the lower atmosphere (modulated somewhat by humidity and cloud cover), while $L W_{\text {net }}$ is generally negative and shows significantly less variability than $S W_{i n}$. As a result, changes in $R n$ are largely associated with variations in sun angle and cloud cover, with the season-mean $R n$ being $\sim 160 \mathrm{~W} \mathrm{~m}^{-2}$. In addition to incoming solar radiation, surface albedo is an important parameter that determines the amount of shortwave radiation that is absorbed at the Earth's surface. Shortwave albedo depends on numerous factors, including sun angle, cloud cover, and surface characteristics (e.g., vegetation, soil, and water). For our study site, the 5-day running mean albedo (5-day $S W_{\text {out }}$ divided by 5-day $S W_{i n}$ ) shows moderate seasonal variation over the course of the growing season in the $P$. australis portion of the wetland (Figure 6). Daily albedo values ranged from a minimum of 0.16 on April 17 to a maximum of 0.24 on June 8. We attribute some of this seasonal increase in albedo to the greening up and "leafing out" of the $P$. australis, which would obscure some of the exposed (and darker) water surface beneath the plant canopy. (No water albedo measurements were made for this study, but Burba et al. (1999b) found open-water albedo values of 0.12 for a similar $P$. australis wetland in central Nebraska.) As illustrated in Figure 6, the P. australis albedo values subsequently declined later in the season (beginning in late July), presumably in response to reductions in LAI in association with senescence (and, possibly, herbicide spraying). Previous studies have also demonstrated the role of LAI and percent vegetation cover in measurements of surface reflectance (e.g., Colwell, 1974; Song, 1999).

Some of the short-term variations in surface albedo that are illustrated in Figure 6 appear to be related to changes in cloud cover, as opposed to vegetation phenology (namely higher albedo during periods of greater cloud cover). It has been found in previous studies (e.g., Lord et al., 1985) that the scattering of diffuse incoming shortwave radiation intercepts more leaf area per unit energy than direct shortwave, thus increasing the shortwave reflectance (see also Guyot and Gu, 1993; Deering and Eck, 1987). The results of these other studies, therefore, are consistent with the pattern exhibited in Figure 6, particularly at the shorter timescales. 


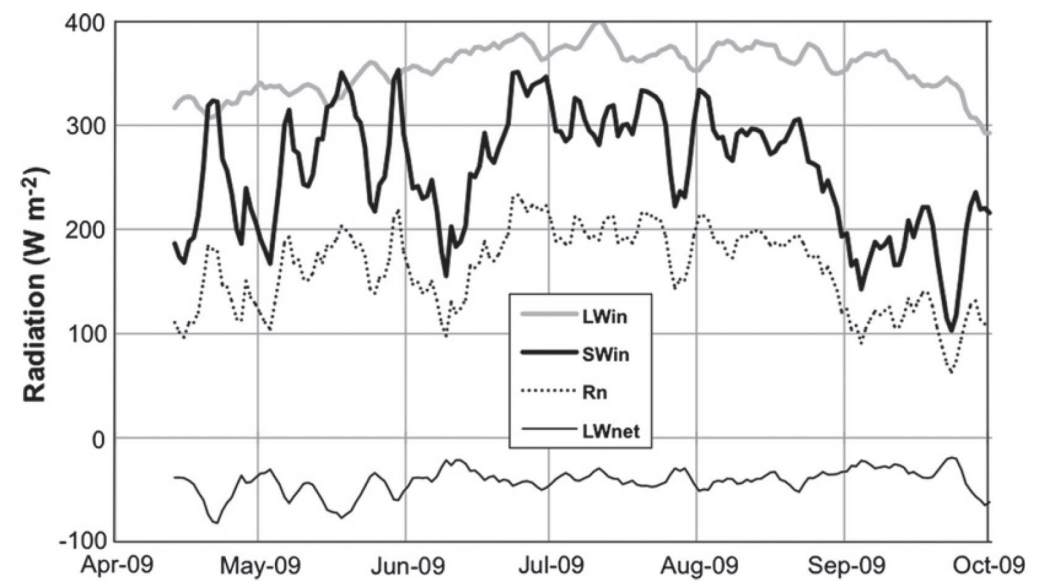

Figure 5. 5-day running mean radiation balance showing the incoming shortwave radiation $\left(S W_{i n}\right)$, incoming longwave $\left(L W_{i n}\right)$, net longwave $\left(L W_{n e t}\right)$, and total net radiation $(R n)$ during the 2009 growing season. Measurements were made at the $P$. australis meteorological station.

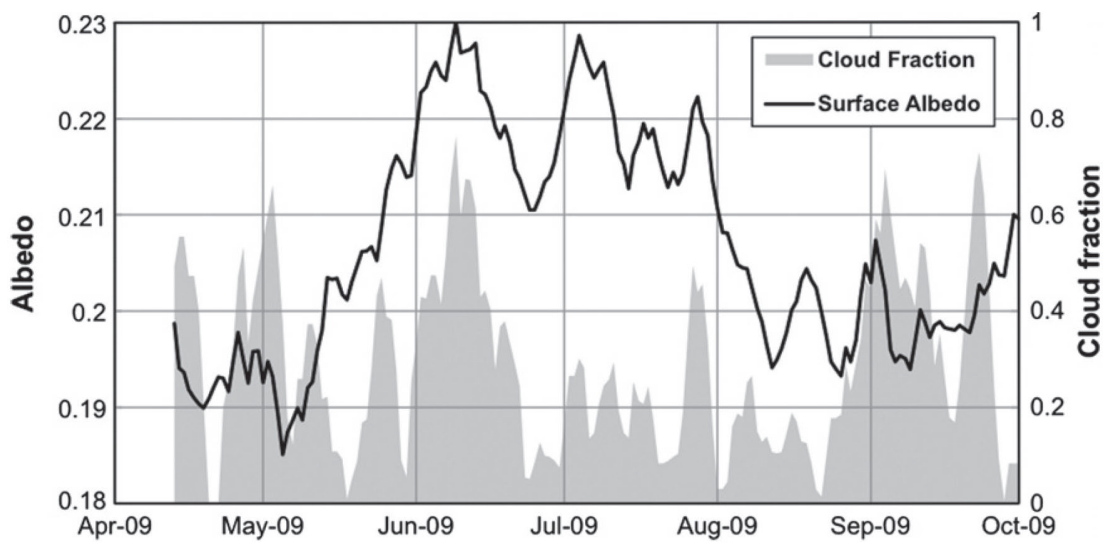

Figure 6. Cloud fraction and shortwave surface albedo measured at the P. australis meteorological station during the 2009 season. Values are based on 5-day running mean measurements of incoming and reflected solar radiation, as well as theoretical clear sky values of incoming solar radiation for the given latitude and time period.

Table 2. Monthly mean energy balance components and Bowen ratio $(B=H / L E)$ for the P. australis portion of the wetland from April 11 to October 3, 2009. (October is included in September's calculations, and April averages represent only a partial month.) Also shown are the standard deviations within each month $( \pm)$, based on the daily mean values. All units are in $\mathrm{W} \mathrm{m}^{-2}$ (except for $B$, which is unitless). The first Bowen ratio value represents the ratio of the monthly mean $H$ and monthly mean $L E$, while parenthetical values for $\mathrm{B}$ show the mean daily Bowen ratio and its standard deviation within that month.

\begin{tabular}{|c|c|c|c|c|c|c|}
\hline & $S W_{i n}$ & $R_{n}$ & $\Delta S / \Delta t$ & $H$ & $L E$ & $B$ \\
\hline May & $275 \pm 98$ & $167 \pm 60$ & $8 \pm 20$ & $49 \pm 28$ & $110 \pm 48$ & $0.45(0.58 \pm 0.44)$ \\
\hline June & $264 \pm 100$ & $169 \pm 66$ & $4 \pm 18$ & $18 \pm 10$ & $147 \pm 56$ & $0.12(0.15 \pm 0.10)$ \\
\hline August & $280 \pm 50$ & $183 \pm 31$ & $2 \pm 10$ & $17 \pm 6$ & $164 \pm 30$ & $0.10(0.11 \pm 0.04)$ \\
\hline September & $185 \pm 62$ & $111 \pm 38$ & $-4 \pm 9$ & $22 \pm 12$ & $93 \pm 37$ & $0.24(0.32 \pm 0.40)$ \\
\hline
\end{tabular}

\subsection{Heat storage rate}

The 5-day running mean heat storage rate of the wetland is shown in Figure 7, broken down into three components: (1) upper soil, (2) deep soil, and (3) total heat storage rate (see Equation (3)). Heat storage in the water column (not shown explicitly in Figure 7) makes up the majority of the total heat storage term, except for times late in the season when water levels were low (Figs. 3a and 7). In general, the rate of heat storage in the upper and deep soil layers is somewhat lagged and has considerably less variability than that of the water (and, therefore, the total). Canopy heat storage (air + vegetation; not shown) is essentially negligible on daily timescales, with a seasonal mean of $-0.02 \mathrm{~W} \mathrm{~m}^{-2}$ and a daily standard deviation $\left(0.67 \mathrm{~W} \mathrm{~m}^{-2}\right)$ that is roughly $4 \%$ that of the total heat storage term (as compared to $6 \%, 22 \%$, and $96 \%$ for the deep soil, upper soil, and water column, respectively). Overall, the daily heat storage rate in the water column ranged from a minimum of $-67.0 \mathrm{~W} \mathrm{~m}^{-2}$ in late April (out of a total heat storage rate of $-61.3 \mathrm{~W} \mathrm{~m}^{-2}$ ) to a maximum of $+51.7 \mathrm{~W} \mathrm{~m}^{-2}$ in early May (out of a total of $+55.9 \mathrm{~W} \mathrm{~m}^{-2}$ ).

As would be expected, there is some correspondence between the daily mean $R n$ and total heat storage rate (Figure 8), with changes in heat storage corresponding to $\sim 13 \%$ of the magnitude of changes in $R n$. On the other hand, changes in $R n$ explain only about $26 \%$ of the variance in the daily heat storage 


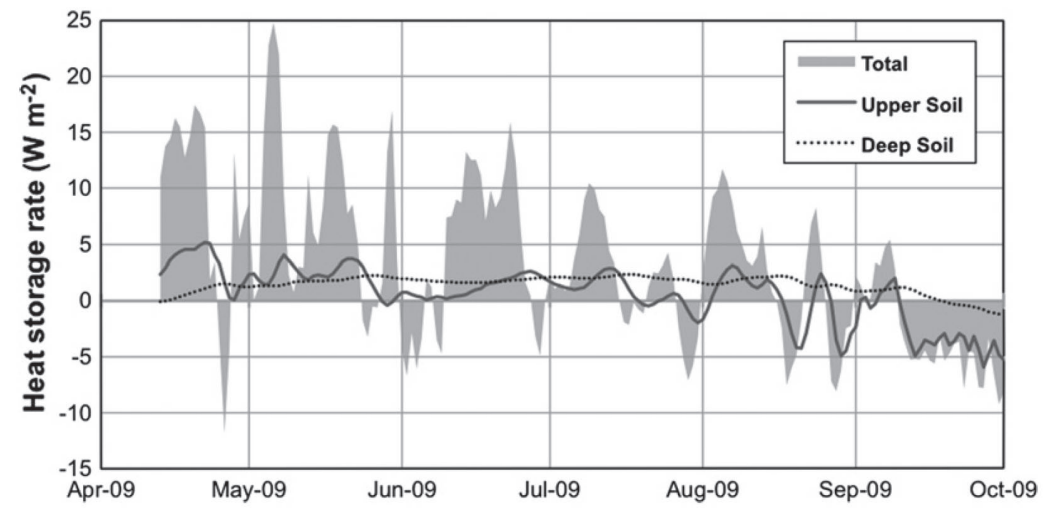

Figure 7. 5-day running mean heat storage rate as measured in the $P$. australis portion of the wetland during the 2009 season. Separate heat storage

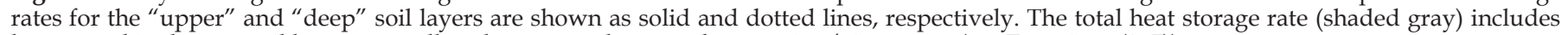
heat stored in the two soil layers, as well as the water column and vegetation/air canopy (see Equations (3-7)).

rate, indicating that sensible and latent heat fluxes also exert significant controls on the water and soil temperatures in the wetland. This is readily evident in Figure 9 as well, which shows each of the 5-day running mean energy balance terms for the 2009 growing season. Many of the short-term and seasonal variations in $R n$ show similar variations in latent and sensible heat flux, leaving significantly less remaining energy to drive the (relatively muted) changes in the heat storage term.

Although the rate of heat storage in the wetland tends to be relatively small on monthly (Table 2), 5-day (Figures 7 \& 9), and even daily timescales (Figure 8), the diurnal range is considerably higher. This is illustrated in Figure 10, which shows the mean diurnal cycle of the various energy balance components for the months of April-May, June-August (JJA), and September-October. (Note that the months of April and October contain only a partial month's data.) On average, the hourly rate of heat storage in the wetland varies similarly to that of $R n$, reaching a maximum heating rate around 11:0013:00 local time and a minimum in the early evening or nighttime hours (Figure 10). Hourly heat storage rates are particularly high during April and May, with average midday heating rates exceeding $150 \mathrm{~W} \mathrm{~m}^{-2}$ (roughly $30 \%$ of the hourly $R n)$. The diurnal range in heat storage rates then declines during JJA (Figure 10b), when latent heat fluxes are much higher and consume a greater fraction of $R n$ than earlier in the season.
Higher LAI during JJA (Figure 4) also leads to significantly greater shading of the underlying water column, which is where most of the diurnal heat storage occurs in the wetland.

In addition to increased shading of incoming solar radiation, the tall, abundant $P$. australis vegetation during JJA serves as an effective thermal "insulator" between the wetland soil/water and the overlying atmosphere. The thick, moist canopy also stores and releases a moderate amount of its own heat on diurnal timescales (maximum of $+24 \mathrm{~W} \mathrm{~m}^{-2}$ and minimum of $-27 \mathrm{~W} \mathrm{~m}^{-2}$ ). In fact, in contrast to daily timescales, hourly variations in the canopy heat storage term (see Equations (3) \& (4)) are actually larger than that of both the upper and deep soil layers. More specifically, the standard deviation of the hourly canopy heat storage term is roughly nine times that of the daily value and comprises $\sim 8 \%$ of the standard deviation in the total hourly heat storage term (compared to $1 \%$, $5 \%$, and $97 \%$ for the deep soil, upper soil, and water column, respectively). Thus, while the rate of heat storage in the wetland continues to be dominated by temperature changes in the water column, the relative significance of the canopy and soil layers depends on both the timescale and the time of year. Finally, we note that - when averaged over the entire growing season - the rate of heat storage in the water column becomes considerably smaller $\left(1.3 \mathrm{~W} \mathrm{~m}^{-2}\right)$ and, in fact, comparable to that of the upper $\left(0.5 \mathrm{~W} \mathrm{~m}^{-2}\right)$ and deep $\left(1.3 \mathrm{~W} \mathrm{~m}^{-2}\right)$ soil layers.

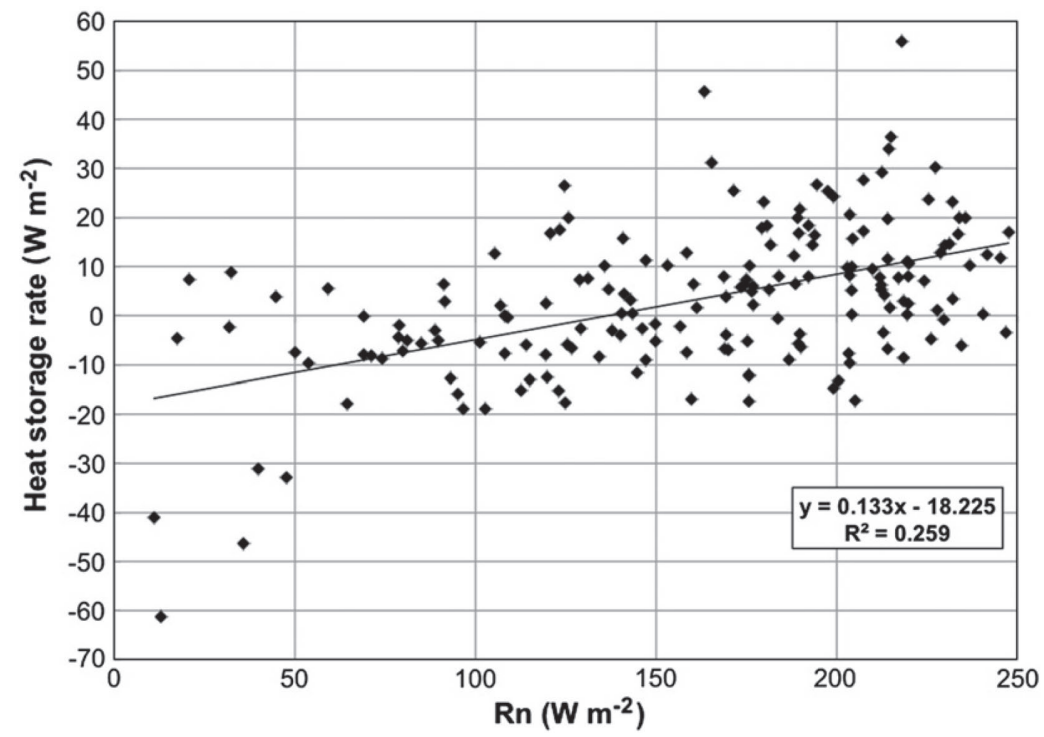

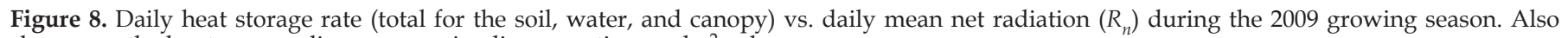
shown are the least-squares linear regression line, equation, and $r^{2}$ value. 


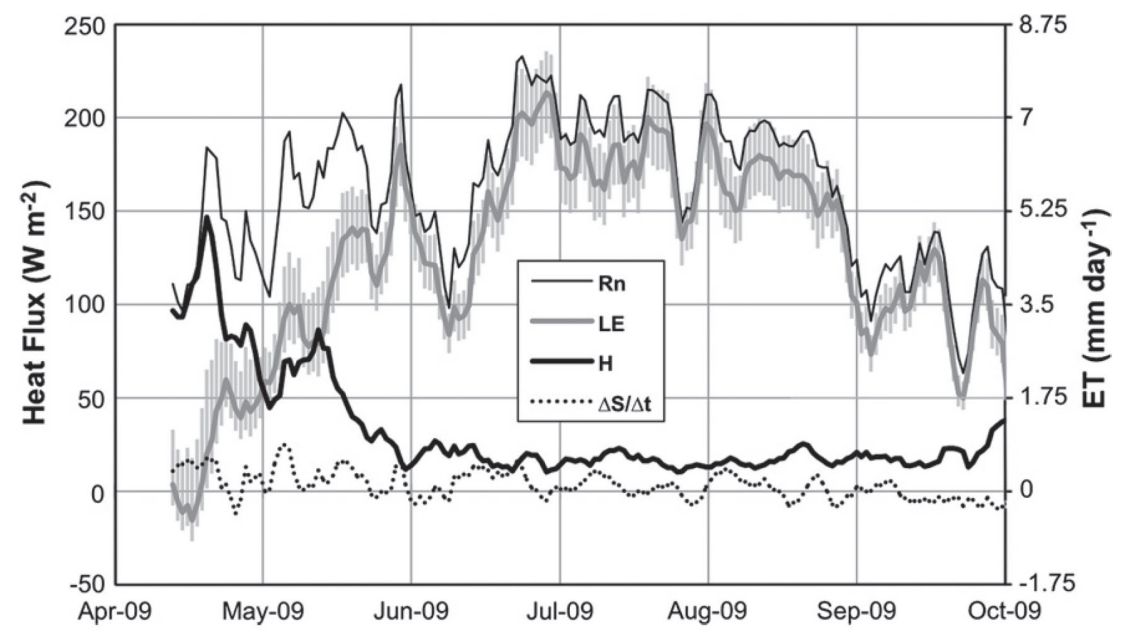

Figure 9. 5-day running mean energy balance components, including net radiation $(R n)$, total rate of change in heat storage $(\Delta S / \Delta t)$, sensible heat flux $(H)$, and latent heat flux ( $L E$; also shown as ET in $\mathrm{mm} \mathrm{day}^{-1}$ on the right hand side). Gray error bars represent the potential error in $L E$ that could result from (cumulative) maximum uncertainties in other energy balance terms.

\subsection{Sensible heat flux}

Results of the 5-day running mean energy balance (Figure 9) reveal significant seasonal variations in the magnitude of the sensible heat flux, with highest 5-day mean values occurring during April and May $\left(\sim 50-150 \mathrm{~W} \mathrm{~m}^{-2}\right)$, prior to the full development of the $P$. australis vegetation (Figure 4). The high sensible heat flux is indicative of the high wind speeds and dry vegetation at this time of year and comprises a significant fraction of the available energy (net radiation minus heat storage rate; see Figure 11). Bowen ratios often exceed 1.0 prior to early May (Figure 11 and Table 2). By early June, sensible heat flux values declined significantly to $\sim 15-20 \mathrm{~W} \mathrm{~m}^{-2}$ in association with corresponding increases in latent heat flux (Figure 9 and Figure 11) and decreases in wind speed (Figure 3d). The sensible heat flux stayed low throughout most of the remaining growing season, aside from a slight increase in late September, presumably in response to higher wind speeds and vegetation senescence.

On hourly timescales, the sensible heat flux shows significant diurnal variability, with maximum values in April and May of $\sim 100-200 \mathrm{~W} \mathrm{~m}^{-2}$. These daily maximums typically occur near or shortly after the maximum in $R n$ (Figure 10), as well as near or shortly before the daily maximum wind speed (not shown; see Cutrell, 2010). Occasional sensible warming of the wetland (i.e., $H<0$ ) was found to occur during the nighttime (at rates of $\sim 30-50 \mathrm{~W} \mathrm{~m}^{-2}$ ), but mean values for $H$ typically hovered around zero at night (Figure 10). Averaged to daily and longer timescales (Table 2 ), $H$ was dominated by the significant daytime sensible cooling. The diurnal range in $H$ was largest during the months of April and May, lowest during the summer period, and slightly higher again in autumn (Figure 10), similar to what was found for the magnitude of the 5-day running mean $H$ (Figure 9).

\subsection{Latent heat flux}

Latent heat flux values showed considerable seasonal variability in the $P$. australis wetland (Figure 9), with minimum values of roughly zero in mid-April to 5-day averages exceeding $200 \mathrm{~W} \mathrm{~m}^{-2}$ in late June (corresponding to a rate of water loss of over $7 \mathrm{~mm} \mathrm{day}^{-1}$ ). The latent heat flux then declined to around $100 \mathrm{~W} \mathrm{~m}^{-2}$ by the end of the season. On daily mean timescales, the minimum $L E$ was $-35.6 \mathrm{~W} \mathrm{~m}^{-2}\left(-1.3 \mathrm{~mm} \mathrm{day}^{-1}\right)$ on April 14, and the maximum was $233.0 \mathrm{~W} \mathrm{~m}^{-2}\left(8.2 \mathrm{~mm}^{-1 a y}{ }^{-1}\right)$ on June 29. (Although somewhat uncertain due to associated error bounds, condensation events early in the season are po- tentially related to the low water temperatures in the wetland in combination with occasional warm, humid air masses.) The maximum daily ET reported in this study is somewhat higher than previously measured $P$. australis ET values of $6.9 \mathrm{~mm} \mathrm{day}^{-1}$ (Smid, 1975), $6.5 \mathrm{~mm} \mathrm{day}^{-1}$ (Burba et al., 1999a), $6.3 \mathrm{~mm} \mathrm{day}^{-1}$ (Fermor et al., 2001), $5.0 \mathrm{~mm} \mathrm{day}^{-1}$ (Peacock and Hess, 2004), and $5.8 \mathrm{~mm}^{-1 a y}{ }^{-1}$ (Zhou and Zhou, 2009) in different regions and under different conditions. On the other hand, a maximum daily ET rate of $\sim 8.0 \mathrm{~mm}^{\text {day }}{ }^{-1}$ was found in an energy balance study of $P$. australis for a different vegetated river system in Nebraska (A. Irmak, personal communication, 8 August 2010), which is within $2-3 \%$ of the value found in the present study.

The high latent heat flux observed at our study site during the height of the growing season was associated with high values of $R n$ (Figure 9). Relatively little of this radiative energy went into sensible heat flux and heat storage during the months of June-August, leaving approximately $90 \%$ of the $R n$ to be partitioned into latent heat flux (Table 2 and Figure 11). On a mean diurnal basis (Figure 10), ET rates followed the timing of $R n$ relatively closely, with maximum values of $\sim 250$ $500 \mathrm{~W} \mathrm{~m}^{-2}$ occurring around 12:00-13:00 local time, and nighttime minimum values hovering around zero. On average, the daytime latent heat flux during JJA exceeded $450 \mathrm{~W} \mathrm{~m}^{-2}$ between the hours of 11:00 and 13:00. This translates into a water loss of almost $2 \mathrm{~mm}$ in a $3-\mathrm{h}$ period. However, the diurnal range in latent heat flux was considerably lower during the beginning and end of the growing season (Figure 10). As noted earlier, this reduced latent heat flux is related to changes in vegetation phenology (Figure 4), greater partitioning of available energy into sensible heat flux ( Figure 9 and Figure 11; Table 2), and seasonal variations in solar radiation (Figure 5). Overall, the average daytime and nighttime $L E$ values measured in the current study were $242.4 \mathrm{~W} \mathrm{~m}^{-2}$ and $6.1 \mathrm{~W} \mathrm{~m}^{-2}$, respectively. The total, accumulated ET throughout the 2009 growing season was $771 \mathrm{~mm}$, which is $64 \%$ higher than the accumulated precipitation of $470 \mathrm{~mm}$. Taking into account all potential sources of error, we estimate that the accumulated ET in the $P$. australis wetland could range between $671 \mathrm{~mm}$ to $895 \mathrm{~mm}$ (i.e., an RMS uncertainty of approximately $13-16 \%$ of the total seasonal ET).

\subsection{Priestley-Taylor ET estimates}

Daily ET estimates were calculated using the P-T method according to Equation (8), and the 5-day running mean values are compared with the energy balance estimates in Figure 12. 
(a) Apr. 11 - May 31

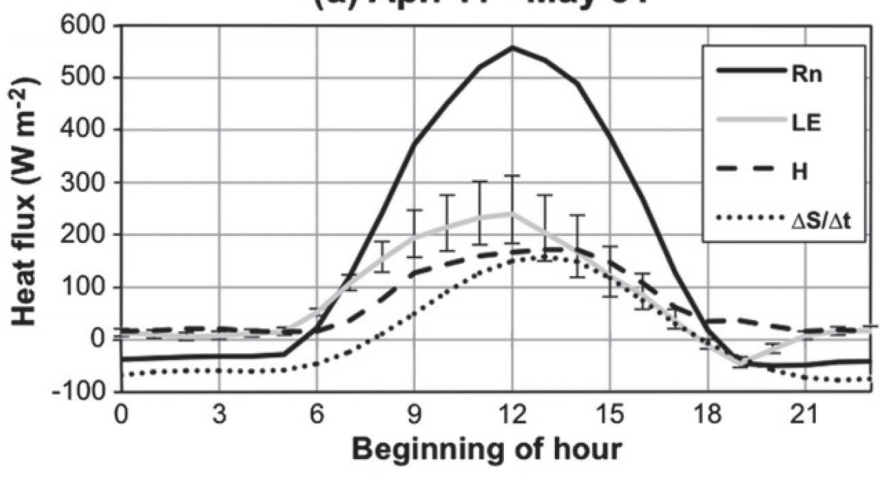

(b) Jun. 1 - Aug. 31

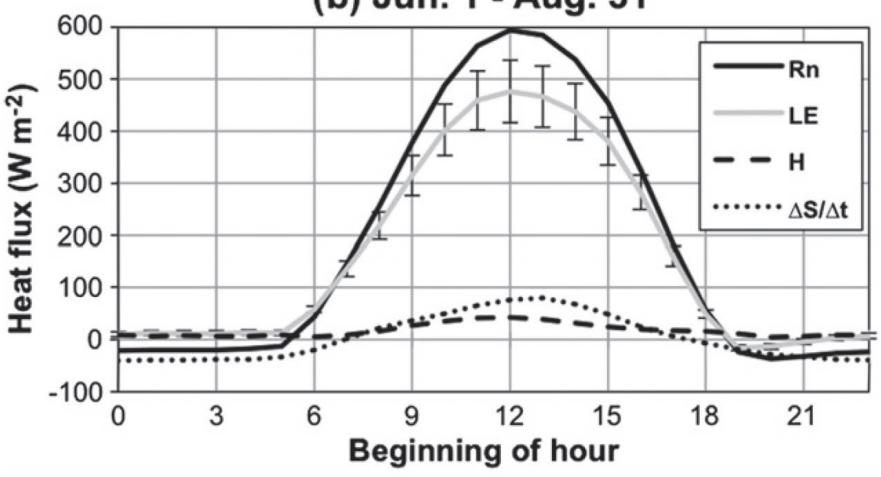

(c) Sep. 1 - Oct. 3

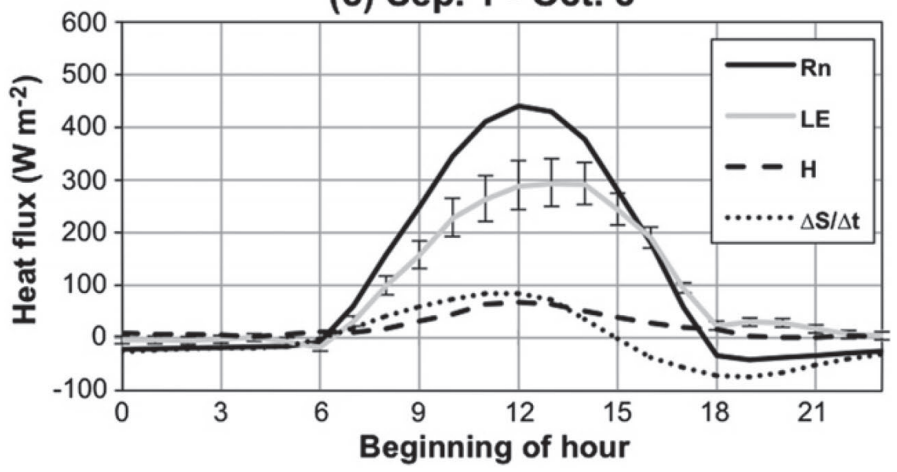

Figure 10. Mean diurnal cycle of the various energy balance components for 2009, averaged over the periods (a) April 11-May 31, (b) June 1-August 31, and (c) September 1-October 3. Shown are the hourly mean net radiation $(R n)$, latent heat flux $(L E)$, sensible heat flux $(H)$, and total heat storage rate $(\Delta S / \Delta t)$. Error bars represent the potential error in $L E$ that could result from (cumulative) maximum uncertainties in other energy balance terms (with uncertainty in the heat storage rate reduced significantly due to the $\sim 1$ - to 3 -month averaging.).
The mean growing-season LE from the P-T method was $139 \mathrm{~W} \mathrm{~m}^{-2}$, which translates into an accumulated ET of $861 \mathrm{~mm}$ (i.e., 12\% higher than the energy balance-derived ET, but still within the $\sim 16 \%$ maximum error bounds). During the majority of the growing season (late May to late September), the 5-day running mean P-T estimates are in very good agreement with the energy balance measurements, lying within the ET error bounds throughout this entire period (Figure 12). Clearly, this agreement reflects the green vegetation and saturated conditions in the $P$. australis wetland during the main growing season, as both of these conditions are appropriate for application of the P-T method. The close correspondence (from June onward) also indicates minimal advection of heat from the surrounding landscape, despite the subhumid climate and narrow wetland corridor. As noted earlier, this is associated - at least in part - with the nearby irrigated cropland (Figure 2), which produces significantly less sensible heat flux than rainfed crops or natural vegetation (e.g., prairie). Thus, the P-T method would be likely to underestimate growingseason ET for narrow riparian corridors in this region, were it not for the well-watered conditions in the surrounding irrigated environment.

Despite the strong performance of the P-T method during the main growing season, significant disagreement with the energy budget-derived ET estimates is evident at the beginning of the season (Figure 12), when the vegetation is predominantly dry and in the very early stages of growth (Figure 4). During April and the first half of May, the P-T method greatly overestimates the rate of ET from the wetland, in some cases by more than a factor of two or three. This reflects the inability of the P-T method (with constant $\alpha$ ) to correctly account for high sensible heat fluxes early in the season (Figures $9 \& 11$ ), when the vegetation is still very dry. Introduction of a seasonally varying $\alpha$ value in the P-T equation (Equation (8)) could potentially be used to scale down the high ET rates early in the season and correct for this discrepancy. A more preferred approach, however, would be to apply a technique such as the Penman-Monteith method, which would explicitly incorporate factors that are associated with the observed changes in latent and sensible heat flux (e.g., variations in stomatal and canopy resistance). Such an approach is beyond the scope of the current study but will be undertaken in future work.

\subsection{Water Balance}

In this section we relate changes in water level to other components of the water balance to provide additional corroboration of the calculated ET rates, as well as to examine the role of groundwater fluxes in the wetland water balance. We do not attempt to provide rigorous closure of the water balance, as groundwater and surface water fluxes were not directly measured. Rather, we simply compare daily water level measurements with timeseries of cumulative $P-E T$, and then interpret the level of agreement or disagreement between these two timeseries (using Equation (10) as a guide). The results

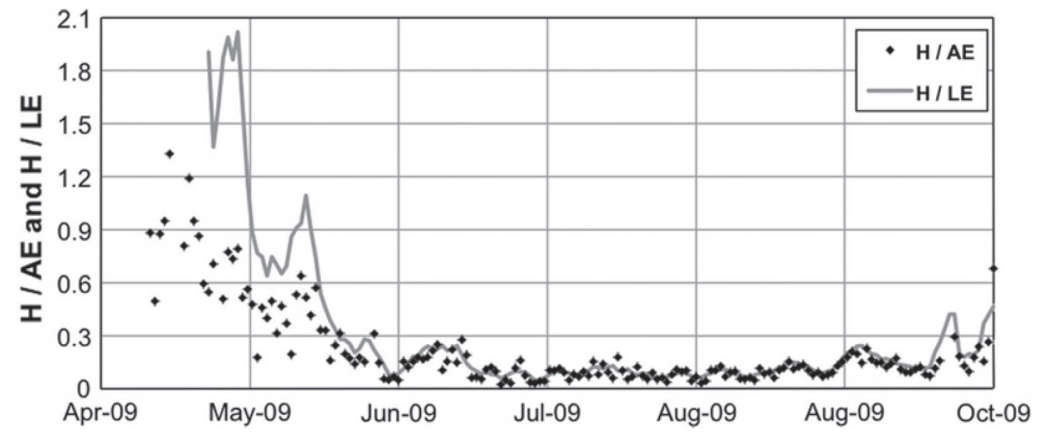

Figure 11. Ratio of the daily mean sensible heat flux $(H)$ to the daily available energy $(A E=R n-\Delta S / \Delta t)$ during the 2009 growing season (solid black diamonds). Also shown is the 5-day Bowen ratio (gray line), in which $B=$ (5-day $H) /(5$-day LE). Note that the Bowen ratio prior to April 23 is not plotted (due to $L E$ values near zero, which leads to large fluctuations in $B$ ). 


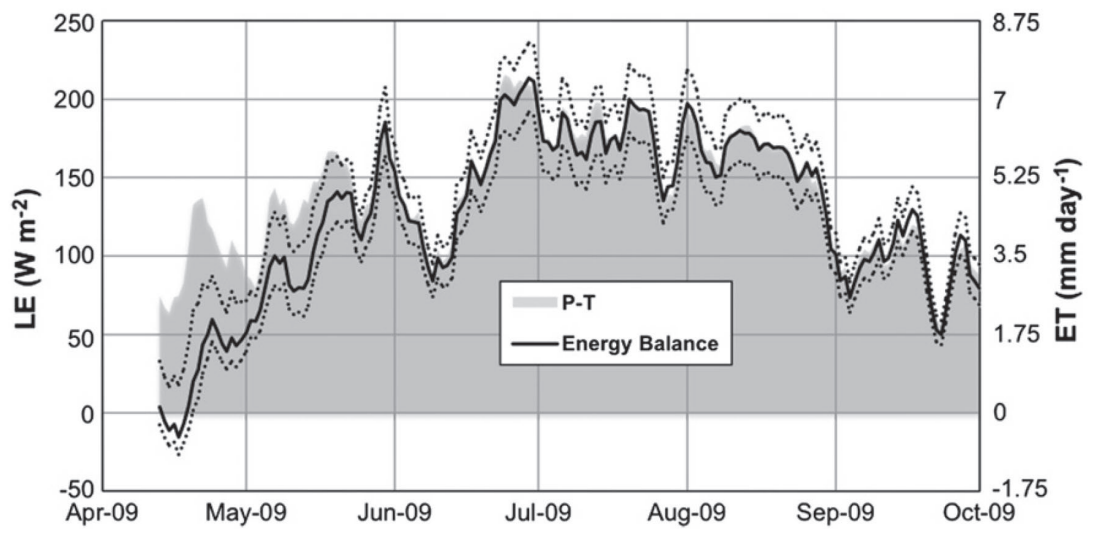

Figure 12. 5-day running mean latent heat flux (expressed in both $\mathrm{W} \mathrm{m}^{-2}$ and $\mathrm{mm} \mathrm{day}^{-1}$ ), as calculated from the energy balance (solid line) and Priestley-Taylor (P-T) equation (shaded gray). Dotted black lines represent the upper and lower error bounds of the energy balance-derived latent heat flux.

are shown in Figure 13 (along with the cumulative precipitation), using the initial wetland water level $\left(L_{0}\right)$ as the starting point for both timeseries. The evolution of the water level $\left(L_{t}\right)$ and cumulative $P-E T$ curves through time is similar, particularly on short timescales (e.g., individual precipitation events) and in terms of the overall trend from the beginning to end of the growing season (with both curves declining by a total of $\sim 30 \mathrm{~cm}$ ). This lends additional credence to the observed precipitation values and energy balance-derived ET rates.

On the other hand, there are also three broad periods of disagreement between the slopes of the two curves (delineated by the two vertical bars in Figure 13). In the first instance (roughly mid-April through mid-June), the wetland water level generally increased at a faster rate than the cumulative $P-E T$ curve. This indicates an additional flux of water into the wetland that was not explicitly measured or accounted for. As noted earlier, we interpret this as a net influx of groundwater (i.e., discharge), since surface flow into or out of the wetland is minimal. By late June, this pattern of net groundwater discharge $\left(G W_{\text {net }}>0\right)$ changes to recharge $\left(G W_{\text {net }}<0\right)$, as reflected in the greater drop in water level relative to the cumulative $P-E T$ curve (Figure 13). This period of recharge continues through late August and may be partly associated with groundwater withdrawals in the nearby agricultural fields, since this is the high water-demand period of the growing season. Finally, by the end of August, the scenario switches back to one of groundwater discharge, and the two water budget terms settle to a similar end-of-season value. This latter observation suggests that the net flux of groundwater into or out of the wetland, when averaged over the entire growing season, is relatively small.

\section{Summary and conclusions}

This study examined the energy and water balance of a wetland in south-central Nebraska that is dominated by an invasive and prolific riparian plant species ( $P$. australis). The goals of the study are to determine the amount of consumptive water use (i.e., ET) by the P. australis wetland during the 2009 growing season (April 11-October 3), as well as to characterize the diurnal to seasonal variability in the energy and water balance and the relative roles of climate variability and vegetation phenology. An LAS system was used to calculate sensible heat flux, while ET (i.e., latent heat flux) was estimated as a residual from the energy balance, which included measurements of net radiation and heat storage rate (in the water, soil, and vegetation canopy). Careful quality control and uncertainty analyses were undertaken to minimize errors and to assess data uncertainty. Ancillary measurements of the local meteorology, wetland water level, and vegetation phenology (i.e., plant height and LAI) provided additional insight into the relevant physical mechanisms.

Using the energy balance method, the total ET during the 2009 growing season was calculated to be $771 \mathrm{~mm}$, with an estimated range of $671-895 \mathrm{~mm}$ (based on the uncertainty analysis). During this same time period, the wetland received $470 \mathrm{~mm}$ of precipitation, leading to a growing-season water deficit of roughly $30 \mathrm{~cm}$. Wetland water levels dropped by

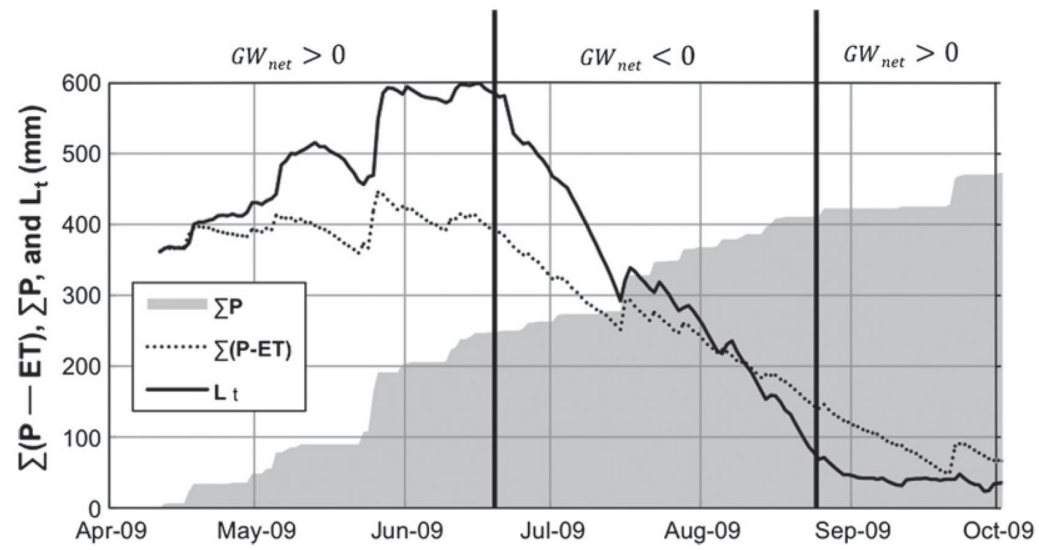

Figure 13. Daily cumulative precipitation ( $\sum P$; shaded gray), wetland water level ( $L_{t} ;$ solid line), and cumulative precipitation minus ET $\left(\sum(P-E T)\right.$; dotted line). ET is calculated from the energy balance, and the initial water level $\left(L_{0}\right)$ is used as the starting point for $\sum(P-E T)$. Thick, vertical lines represent transitions between periods of net groundwater influx $\left(G W_{n e t}>0\right)$ and outflux $\left(G W_{n e t}<0\right)$. Surface inflow/outflow is assumed to be negligible relative to other water balance components (see Equation (10)). 
approximately the same amount from April to October, indicating that the net flux of water from other sources (primarily groundwater) was relatively small. On shorter timescales, however, it was clear that the wetland experienced a net influx of groundwater early and late in the season, but was a source of groundwater recharge during the height of the growing season (late June to late August).

Average ET over the 176-day growing season equated to a mean rate of water loss of $4.4 \pm 0.7 \mathrm{~mm} \mathrm{day}^{-1}$, although the seasonal variability in ET was found to be considerable. For example, the maximum daily ET rate was $8.2 \mathrm{~mm} \mathrm{day}^{-1}$ (on June 29), while the minimum was $-1.3 \mathrm{~mm} \mathrm{day}^{-1}$ (on April 14). Condensation events early in the season were not uncommon, but the magnitudes were generally not large enough to be considered significantly different from zero (based on the energy balance uncertainty analysis). Also, it is important to note that the ET rates calculated in this study do not distinguish between transpiration and open water (or intercepted) evaporation. Aside from the $9 \%$ of the wetland area that is classified as open water, we would not expect significant amounts of evaporation from the water that is directly below the P. australis, at least during the height of the growing season. At this time of the year, the tall, dense vegetation leads to significant shading of solar radiation, cold water temperatures, and calm, humid conditions within the canopy. The only time when evaporation directly from the water surface is likely to comprise a significant fraction of the total ET is during the early part of the season (April-May), when LAI values are low and the atmosphere is relatively dry and windy.

The strong seasonal variability in latent heat flux (noted above) was found to be associated with similar (but reciprocal) changes in sensible heat flux. Early in the season, when conditions were windier and the vegetation was dry, most of the available energy was partitioned into sensible heat flux, with Bowen ratios often exceeding 1.0 (and averaging 4.3 for the period 11-30 April). Although the wetland contains moderately cool water during this time of year (relative to the overlying air), the tall, dry vegetation - which is easily warmed by incoming solar radiation-clearly dominates the flux of sensible heat into the atmosphere. In this sense, then, the wetland behaves more like a dry, grassy field during much of the spring season, rather than a typical "water body." By mid-May, however, the vegetation had greened up considerably, leading to a significant increase in latent heat flux, a corresponding decrease in sensible heat flux, and Bowen ratios of around 0.5. During the main part of the growing season (LAI $=4.0-5.4$, vegetation height $=3.5-4.2 \mathrm{~m})$, roughly $90 \%$ of the available energy was consumed by latent heat flux, with daily and monthly Bowen ratios around 0.1. ET rates during this time period were very closely approximated by the Priestley-Taylor formula, but this method was found to perform poorly during the earlier, dry part of the season. By late August, net radiation and latent heat flux began to decline, while sensible heat flux remained constant and eventually increased in late September (in association with vegetation senescence and higher wind speeds). In terms of the diurnal variability, both sensible and latent heat fluxes showed a considerable daily range throughout the growing season, with large maximums around midday and values near zero during the night.

The rate of heat storage in the wetland was found to be a relatively insignificant component of the monthly mean energy balance, consuming roughly $8 \%$ of the net radiation in April, and less than $4 \%$ during most of the remaining growing season. On daily mean timescales, the rate of heat storage was more variable, with a standard deviation up to five times the monthly mean value and changes in heat storage rate that corresponded to $\sim 13 \%$ that of the daily mean net radiation. Diurnal variations in heat storage were much stronger, with a daily range (averaging 100-200 $\mathrm{W} \mathrm{m}^{-2}$ ) that often matched or exceeded that of the sensible heat flux. Except when water levels were low, the rate of heat storage in the water column was found to be (by far) the most dominant heat storage term. The next most significant components were the upper and deep soil layers, particularly for long timescales. Heat storage rates within the vegetation canopy were generally negligible, except on hourly timescales during the height of the growing season, when they often exceeded the rate of heat storage in the soil layers (but not the water).

The invasive $P$. australis vegetation was sprayed with herbicide on July 22, 2009 to monitor the response of the wetland energy and water balance to vegetation "removal." Although observations in the spring and summer of 2010 clearly indicate that the vegetation has, in fact, been killed, we found little evidence of an immediate response in August or September of 2009. Some reduction in LAI and shortwave albedo (the latter perhaps being due to greater exposure to open water) was observed shortly after the spraying. But it is difficult to assess whether or not this may simply have been due to natural autumn senescence. The ratio of latent heat flux to available energy, for example, remained unchanged at $\sim 90 \%$ through June, July, and August, and dropped to only $81 \%$ in September. This suggests that the herbicide treatment had minimal immediate effects on transpiration rates in the late summer and early autumn. Future observational and modeling work will document the more substantial impacts of the spraying on the 2010 energy and water balance. This will help to provide an assessment of the potential amount of "water savings" that might be realized in the Republican River basin (and similar semi-arid to subhumid climates) as a result of removing invasive $P$. australis vegetation from riparian zones.

Acknowledgments - The authors would like to thank E. Soylu, K. Von Buettner, S. Walters, T. Wang, and P. Mykleby for field assistance. We would also like to acknowledge D. Hatch, A. Suyker, and S. Verma for providing eddy covariance data from the Mead Ameriflux site, as well as the National Climatic Data Center (NCDC) and High Plains Regional Climate Center (HPRCC) for the COOP and AWDN data, respectively. We appreciate the assistance of V. Cassella at Kipp \& Zonen USA, Inc. for answering questions related to LAS instrumentation and software. Funding for this study was provided by the Nebraska Environmental Trust (NET), the University of Nebraska Water Resources Advisory Panel (WRAP), and the University of Nebraska Rural Initiative. G. Cutrell would like to thank the School of Natural Resources at the University of Nebraska-Lincoln for providing a graduate research assistantship to fund his M.S. thesis work.

\section{References}

Brekke, L. D., Kiang, J. E., Olsen, J. R., Pulwarty, R. S., Raff, D. A., Turnipseed, D. P., Webb, R. S., White, K. D., 2009. Climate change and water resources management - a federal perspective, US Geological Survey Circular 1331, $65 \mathrm{pp}$.

Burba, G. G., Verma, S. B., Kim, J., 1999a. Surface energy fluxes of Phragmites australis in a prairie wetland. Agricultural and Forest Meteorology 94, 31-51.

Burba, G. G., Verma, S. B., Kim, J., 1999b. A comparative study of surface energy fluxes of three communities (Phragmites australis, Scirpus acutus, and open water) in a prairie wetland ecosystem. Wetlands 19 (2), $451-457$

Burt, O. R., Baker, M., Helmers, G. A., 2002. Statistical estimation of streamflow depletion from irrigation wells. Water Resources Research 38 (12), 1296.

Chehbouni, A., Watts, C., Lagouarde, J.-P., Kerr, Y. H., Rodriguez, J.-C., Bonnefond, J.- M., Santiago, F., Dedieu, G., Goodrich, D. C., Unkrich, C., 2000. Estimation of heat and momentum fluxes over complex terrain using a large aperture scintillometer. Agricultural and Forest Meteorology 150, 215-226.

Chen, B., Chen, J. M., Ju, W., 2007. Remote sensing-based ecosystem-atmosphere simulation scheme (EASS) - model formulation and test with multiple-year data. Ecological Modelling 209, 277-300.

Clifford, S. F., Ochs, G. R., Lawrence, R. S., 1974. Saturation of optical scintillation by strong turbulence. Journal of Optical Society of America 64 (2), 148-154. 
Colwell, J. E., 1974. Vegetation canopy reflectance. Remote Sensing of Environment 3, 175-183.

Cutrell, G. J., 2010. Seasonal energy and water balance of a Phragmites australis-dominated wetland in the Republican River basin (southwestern Nebraska, USA). Master's Thesis, University of Nebraska, Lincoln. 128 pp.

De Bruin, H. A. R., Keijman, J. Q., 1979. The Priestley-Taylor evaporation model applied to a large, shallow lake in the Netherlands. Journal of Applied Meteorology 18, 898-903.

Deering, D. W., Eck, T. F., 1987. Atmospheric optical depth effects on angular anisotropy of plant canopy reflectance. International Journal of Remote Sensing 8 (6), 893-916.

Ezzahar, J., Chehbouni, A., Hoedjes, J. C. B., Er-Raki, S., Chehbouni, Ah., Boulet, G., Bonnefond, J.-M., De Bruin, H. A. R., 2007. The use of scintillation technique for monitoring season water consumption of olive orchards in a semi-arid region. Agricultural Water Management 89, 173-184.

Fermor, P. M., Hedges, P. D., Gilbert, J. C., Gowing, D. J. G., 2001. Reedbed evapotranspiration rates in England. Hydrological Processes 15, 621-631.

Gray, S. T., McCabe, G. J., 2010. A combined water balance and tree ring approach to understanding the potential hydrologic effects of climate change in the central Rocky Mountain region. Water Resources Research 46, W05513. doi:10.1029/2008WR007650.

Grothues, T. M., Able, K. W., 2003. Response of juvenile fish assemblages in tidal salt marsh creeks treated for Phragmites removal. Estuaries and Coasts $26(2), 563-573$.

Guyot, G., Gu, X. F., 1993. Measurement of plant canopy reflectance. In: Varlet- Grancher, C., Bonhomme, R., Sinoquet, H. (Eds.), Crop Structure and Light Microclimate: Characterization and Applications. INRA Editions, pp. 323-335.

Hartogensis, O. K., Watts, C. J., Rodriguez, J. C., De Bruin, H. A. R., 2003. Derivation of an effective height for scintillometers: La Poza experiment in northwest Mexico. Journal of Hydrometeorology 4, 915-928.

Higuchi, A., Hiyama, T., Fukuta, Y., Suzuki, R., Fukushima, Y., 2007. The behavior of a surface temperature/vegetation index (TVX) matrix derived from 10-day composite AVHRR images over monsoon Asia. Hydrological Processes 21, 1157-1166.

Hoedjes, J. C. B., Zuurmbier, R. M., Watts, C. J., 2002. Large aperture scintillometer used over homogenous irrigated area, partly affected by regional advection. Boundary-Layer Meteorology 105, 99-117.

Irmak, S., Personal Interview, 8 August 2010.

Jia, L., Xi, G., Liu, S., Huang, C., Yan, Y., Liu, G., 2009. Regional estimation of daily to annual regional evapotranspiration with MODIS data in the Yellow River Delta wetland. Hydrology and Earth System Sciences 13 (10), 1775-1787.

Kansas Department of Agriculture, 2010. Fact Sheet: Republican River Compact Enforcement.

Kipp \& Zonen USA, Inc., 2007. Large Aperture Scintillometer Manual.

Kiviat, E., 2006. Phragmites management sourcebook for the tidal Hudson River and the northeastern states. Hudsonia Ltd., Annandale, NY; http://hudsonia.org

Kleissl, J., Gomez, J., Hong, S.-H., Hendrickx, J. M. H., Rahn, T., Defoor, W. L., 2008. Large aperture scintillometer intercomparison study. Boundary-Layer Meteorology 128, 133-150.

Kohsiek, W., Meijninger, W. M. L., De Bruin, H. A. R., Beyrich, F., 2006. Saturation of the large aperture scintillometer. Boundary-Layer Meteorology $121,111-126$.

Lord, D., Desjardins, R. L., Dube, P. A., Brach, E. J., 1985. Variations of crop canopy spectral reflectance measurements under changing sky conditions. Photogrammetric Engineering and Remote Sensing 51 (6), 689-695.

Meijninger, W. M. L., Beyrich, F., Ludi, A., Kohsiek, W., De Bruin, H. A. R., 2006. Scintillometer-based turbulent fluxes of sensible and latent heat over a heterogeneous land surface - a contribution to LITFASS-2003. Boundary-Layer Meteorology 121, 89-110.

Monteiro, A., Moreira, I., Sousa, E., 1999. Effect of prior common reed (Phragmites australis) cutting on herbicide efficacy. Hydrobiologia 415, 305-308.

Moore, C. J., Fisch, G., 1986. Estimating the heat storage in Amazonian tropical forest. Agriculture Forest Meteorology 38, 147-168.

Moro, M. J., Domingo, F., Lopez, G., 2004. Seasonal transpiration pattern of Phragmites australis in a wetland of semi-arid Spain. Hydrological Processes 18, 213-227.

Mujumdar, P. P., 2008. Implications of climate change for sustainable water resources management in India. Physics and Chemistry of the Earth 33 (5), 354-358

NCDC, 2009. National Climatic Data Center; http://www.ncdc.noaa.gov

Peacock, C. E., Hess, T. M., 2004. Estimating evapotranspiration from a reed bed using the Bowen ratio energy balance method. Hydrological Processes 18, 247-260.
Pelleschi, S., Rocher, J.-P., Prioul, J.-L., 1997. Effect of water restriction on carbohydrate metabolism photosynthesis in mature maize leaves. Plant, Cell and Environment 20, 493-503.

Priestley, C. H. B., Taylor, R. J., 1972. On the assessment of surface heat flux and evaporation using large-scale parameters. Monthly Weather Review $100,81-82$

Randow, C. V., Kruijt, B., De Oliveira, M. B. L., 2008. Exploring eddy-covariance and large-aperture scintillometer measurements in an Amazonian rain forest. Agricultural and Forest Meteorology 148, 680-690.

Rosenberry, D. O., Sturrock, A. M., Winter, T. C., 1993. Evaluation of the energy budget method of determining evaporation at Williams Lake, Minnesota, using alternative instrumentation and study approaches. Water Resources Research 29 (8), 2473-2483.

Rosenberry, D. O., Stannard, D. I., Winter, T. C., Martinez, M. L., 2004 Comparison of 13 equations for determining evapotranspiration from a prairie wetland, Cottonwood Lake area, North Dakota, USA. Wetlands 24 (3), 483-497.

Sánchez-C, S., Angeler, D. G., Sánchez-A, R., Alvarez-C, M., Garatuza-P, J. 2004. Evapotranspiration in semi-arid wetlands: relationships between inundation and the macrophyte-cover:open-water ratio. Advances in Water Resources 27, 643-655.

Smart, R. E., Bingham, G. E., 1974. Rapid estimates of relative water content. Plant Physiology 53, 258-260.

Smid, P., 1975. Evaporation from a reedswamp. Journal of Ecology 31 (1) 299- 309.

Song, J., 1999. Phenological influences on the albedo of prairie grassland and crop fields. International Journal of Biometeorology 42, 153-157.

Stewart, R. B., Rouse, W. R., 1976. A simple method for determining the evaporation from shallow lakes and ponds. Water Resources Research $12(4), 623-628$

Suyker, A. E., Verma, S. B., 2010. Coupling of carbon dioxide and water vapor exchanges of irrigated and rainfed maize-soybean cropping systems and water productivity. Agricultural and Forest Meteorology 150, 553-563.

Szilagyi, J., 1999. Streamflow depletion investigations in the Republican River basin: Colorado, Nebraska, and Kansas. Journal of Environmental Systems 27 (3), 251- 263.

Szilagyi, J., 2001. Identifying cause of declining flows in the Republican River. Journal of Water Resources Planning and Management 127 (4), 244-253.

Szwed, M., Karg, G., Pinskwar, I., Radziejewski, M., Graczyk, D., Kedziora, A., Kundzewicz, Z. W., 2010. Climate change and its effect on agriculture, water resources and human health sectors in Poland. Natural Hazards and Earth Systems Sciences 10 (8), 1725-1737.

Thom, A. S., 1975. Momentum, Mass and Heat Exchange of Plant Communities. Vegetation and the Atmosphere, vol. 1. Academic Press, New York, pp. 57- 109 .

Thornthwaite, C. W., 1948. An approach toward a rational classification of climate. Geographical Review 38 (1), 55-94.

Twine, T. E., Kustas, W. P., Norman, J. M., Cook, D. R., Houser, P. R., Meyers, T. P., Prueger, J. H., Starks, P. J., Wesely, M. L., 2000. Correcting eddy-covariance flux underestimates over a grassland. Agricultural and Forest Meteorology 103, 279-300.

Virginia Department of Conservation and Recreation, 2007. Marsh Invader! How to identify and combat one of Virginia's most invasive plants: Phragmites.

Wang, T., Ochs, G. R., Clifford, S. F., 1978. A saturation-resistant optical scintillometer to measure $\mathrm{C}^{2}{ }_{n}$. Journal of the Optical Society of America 68 (3), 334-338.

Wen, F., Chen, X., 2006. Evaluation of the impact of groundwater irrigation on streamflow in Nebraska. Journal of Hydrology 327, 603-617.

Wesely, M. L., 1976. The combined effect of temperature and humidity fluctuations on refractive index. Journal of Applied Meteorology 15, 43-49.

Wilcox, D. A., Whillans, T. H., 1999. Techniques for restoration of disturbed coastal wetlands of the Great Lakes. Wetlands 19 (4), 835-857.

Wilson, K., Goldstein, A., Falge, E., Aubinet, M., Baldocchi, D., Berbigier, P., Bernhofer, C., Ceulemans, R., Dolman, H., Field, C., Grelle, A Ibrom, A., Law, B. E., Kowalski, A., Meyers, T., Moncrieff, J., Monson, R., Oechel, W., Tenhunen, J., Valentini, R., Verma, S., 2002. Energy balance closure at FLUXNET sites. Agricultural and Forest Meteorology $113,223-243$

Wyngaard, J. C., Izumi, Y., 1971. Behavior of the refractive-index-structure parameter near the ground. Journal of the Optical Society of America 61 (12), 1646-1650

Zhou, L., Zhou, G., 2009. Measurement and modeling of evapotranspiration over a reed (Phragmites australis) marsh in Northeast China. Journal of Hydrology 372, 41-47. 